DOE-PC-89877-7

Dist. Cat. U.C. $-90 d$

\title{
CATALYST DISPERSION AND ACTIVITY UNDER CONDITIONS OF TEMPERATURE-STAGED LIQUEFACTION
}

Technical Progress Report for the Period April to June 1991

by

Alan Davis, H.H. Schobert, G.D. Mitchell and L. Artok

Energy and Fuels Research Center and Fuel Science Department The Pennsylvania State University

University Park, PA 16802

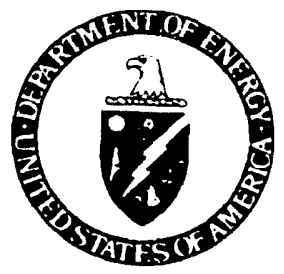

Date Published, September 1991

PREPARED FOR THE UNITED STATES

DEPARTMENT OF ENERGY under

Contract No. DE-AC22-89PC89877 


\title{
CATALYST DISPERSION AND ACTIVITY UNDER CONDITIONS OF TEMPERATURE-STAGED LIQUEFACTION
}

\section{Technical Progress Report for the Period April to June 1991}

by

\author{
Alan Davis, H.H. Schobert, G.D. Mitchell \\ and L. Artok
}

\section{DISCLAIMER}

This report was prepared as an account of work sponsored by an agency of the United States Government. Neither the United States Government nor any agency thereof, nor any of their employees, makes any warranty, express or implied, or assumes any legal liability or responsibility for the accuracy, completeness, or usefulness of any information, apparatus, product, or process disclosed, or represents that its use would not infringe privately owned rights. Reference herein to any specific commercial product, process, or service by trade name, trademark, manufacturer, or otherwise does not necessarily constitute or imply its endorsement, recommendation, or favoring by the United States Government or any agency thereof. The views and opinions of authors expressed herein do not necessarily state or reflect those of the United States Government or any agency thereof.

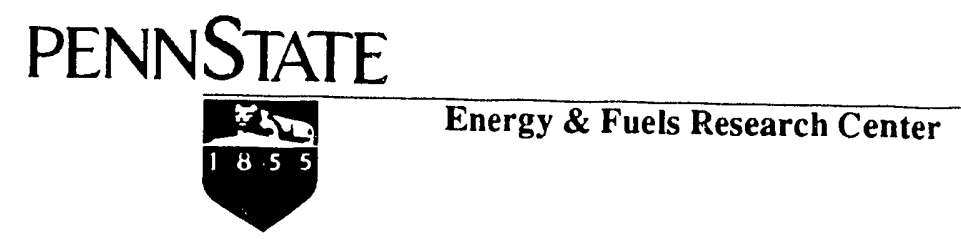

(814) 865-6544 


\section{DISCLAIMER}

This report was prepared as an account of work sponsored by an agency of the United States Government. Neither the United States Government nor any agency thereof, nor any of their employees, makes any warranty, express or implied, or assumes any legal liability or responsibility for the accuracy, completeness, or usefulness of any information, apparatus, product, or process disclosed, or represents that its use would not infringe privately owned rights. References herein to any specific commercial product, process, or service by trade name, trademark, manufacturer, or otherwise does not necessarily constitute or imply its endorsement, recommendation, or favoring by the United States Government or any agency thereof. The views and opinions of authors expressed herein do not necessarily state or reflect those of the United States Government or any agency thereof. 
ABSTRACT

Temperature-staged liquefaction experiments $\left(275^{\circ} \mathrm{C}, 30 \mathrm{~min} ; 425^{\circ} \mathrm{C}, 30\right.$ min) have been preformed on preswollen coals with ammonium tetrathiomolybdate (ATTM) and with bis (dicarbonylcyclopentadienyl) iron (CPI). Liquefaction results and ${ }^{13} \mathrm{C}$ NMR data suggest that ATTM enhanced coal dissolution contributing to a greater formation of asphaltenes and 0i1. Preswelling the Blind Canyon coal (DECS-6) in tetrahydrofuran (THF) and pyridine increased oil formation in the presence of ATTM, but tetrabutylammonium hydroxide (TBAH) treatment appeared to be detrimental for this coal. On the other hand, TBAH and pyridine treatment enhanced liquefaction of the Texas lignite whether ATTM was present or absent.

The CPI catalyst has been tested because of the difficulty experienced with impregnating coal with iron pentacarbonyl. Preliminary two-stage liquefaction results using CPI showed that better liquefaction results were obtained using $\mathrm{H}_{2} \mathrm{~S}: \mathrm{H}_{2}$ gas mixture and high temperature reaction to promote the formation of the active catalyst phase pyrrhotite. Furthermore, the use of pyridine as swelling reagent with CPI produced lower total conversion with the Blind Canyon coal and about equal conversion of the Texas lignite compared with preswelling in methanol.

SEM and electron microprobe analyses were performed on Blind Canyon and Texas lignite coal samples that were first swollen in solvents and then impregnated with ATTM. Results show that the use of water and pyridine may provide a better submicron dispersion of ATTM catalyst on the Blind Canyon 
coal then when methanol was used as a swelling reagent. However, water and methanol provide a more uniform dispersion of ATTM on the Texas lignite compared with pyridine.

Finally, three reactor solid deposit samples from wilsonville run 260 using the Black Thunder subbituminous coal were characterized in our cooperative research task. Run 260 was operated in the catalytic/thermal mode with lower first-stage and higher second-stage temperatures in an attempt to eliminate retrogressive reactions and coke formation. Deposit materials were confined to the second-stage thermal reactor. $x$-ray diffraction and optical microscopy showed that the reactor deposits were formed predominantly as a result of the formation, accretion and deposition of calcium carbonate. Formation of mesophase-derived carbon was minimized by the reaction conditions, but there was a proportionally higher concentration of secondary vitroplast, an isotropic process-derived insoluble material. Consequently, the reaction conditions were successful in reducing coke formation, but did not fully eliminate retrogressive reactions. 
Page

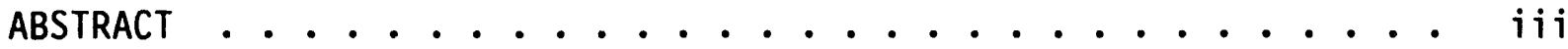

PROGRAM OBJECTIVES . . . . . . . . . . . . . . . . . . 1

PROGRAM OUTLINE ......................... . . . 1

Catalyst Transformation .................... 1

Catalysts and Their Dispersion . . . . . . . . . . . . . 2

Coal Pretreatment . . . . . . . . . . . . . . . . . . 3

Evaluation of Impregnated Coals and Residual Materials
from Other DOE Programs . . . . . . . . . . . . . . 5

DESCRIPTION OF TECHNICAL PROGRESS . . . . . . . . . . . . . 6

1. THE EFFECTS OF PRESWELLING AND CATALYST PRECURSORS ON

LIQUEFACTION OF COALS ................... 6

1.1. Introduction ................ 6

1.2. Experimental ................. 6

1.2.1. The Swelling Procedure and Catalyst Impregnation of Coals ................. . . 6

1.2.2. Liquefaction Experiments and Product Work-up . 7

1.3. Results and Discussion ............. 7

1.4. Conclusions ................ 22

References ................... 24

2. CATALYST DISPERSION ON COALS . . . . . . . . . . 25

2.1. Introduction ................ 25

2.2. Experimental ............... 25

2.3. Results and Discussion ............ 26

2.4. Conclusions .................. 36

References ................ 36 
3. EVALUATION OF MATERIALS FROM OTHER DOE PROGRAMS ...... 37

3.1. Introduction ................ 37

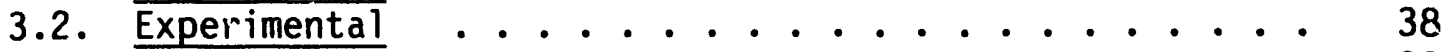

3.3. Results and Discussion ........... 38

3.4. Conclusions ................. 43

References ...................... 44 
PROGRAM OBJECTIVES

The general objectives of this research are 1) to investigate the use of highly dispersed catalysts for the pretreatment of coal by mild hydrogenation, 2) to identify the active forms of the catalysts under reaction conditions and 3 ) to clarify the mechanisms of catalysis. The ultimate objective is to ascertain if mild catalytic hydrogenation resulting in very limited or no coal solubilization is an advantageous pretreatment for the transformation of coal into transportable fuels. The experimental program will focus upon the development of effective methods of impregnating coal with catalysts, evaluating the conditions under which the catalysts are most active and establishing the relative impact of improved impregnation on conversion and product distributions obtained from coal hydrogenation.

PROGRAM OUTLINE

\section{Catalyst Transformation}

Four catalyst materials have been selected for this investigation: ammonium tetrathiomolybdate, ferrous sulfate, molybdenum hexacarbonyl, and iron pentacarbonyl. Insofar as it is possible, these catalysts will be evaluated by TGA in order to determine 1) the temperature at which a chemical change occurs in the catalyst precursor, 2) the holding time at that temperature needed to reach completion of the transformation, and 3 ) and effects of heating rate on catalyst precursor transformation. Experiments will be performed for each catalyst for a matrix of conditions, 
as follows: 1) three heating rates: $5^{\circ}, 50^{\circ}$, and about $125^{\circ} \mathrm{C} / \mathrm{min}$; 2)

three final temperatures: $275^{\circ}, 350^{\circ}$, and $425^{\circ} \mathrm{C} ; 3$ ) two atmospheres, riamely nitrogen and hydrogen; and 4) one "soak time" at temperature (1 h). Also, in order to define the heating regimes over which both catalysts and coals decompose, each of the two test coals will be evaluated in the TGA under the same reaction conditions employed with the catalysts.

Each of the catalyst precursors will be tested in $25 \mathrm{Ml}$ microautoclaves (tubing bombs) in order to prepare larger quantities of the transformed materials for subsequent characterization. The timetemperature regimes used in these experiments will be selected based on results from the TGA study. Three atmospheres will be used: 1) nitrogen, 2) hydrogen, and 3) 95:5 hydrogen:hydrogen sulfide. In each of these experiments the tubing bomb will be pressurized to 1000 psi (cold).

\section{Catalysts and Their Dispersion}

The purpose of this portion of the research effort is to investigate methods of impregnating coal with catalysts prior to liquefaction. A variety of techniques that are best suited for a particular catalyst will be explored. Those planned include:

a) using the ammonium tetrathiomolybdate or ferrous sulfate in aqueous solution; the coais will be slurried with the solution of catalyst precursor and then freeze-dried;

b) these same precursors will be applied to coal in solvents that are known to swell coal structures; THF, pyridine, methanol and tetrabutylammonium hydroxide. However, the catalyst materials must be either soluble or form a fairly stable suspension in the appropriate solvent in order to promote access of catalyst to interior surfaces of the coal; 
c) iron pentacarbonyl and molybdenum hexacarbonyl will be applied to coal in hydrocarbon or other organic solvents that may promote coal swelling;

d) ion exchange of iron, as ferrous sulfate, onto the lignite selected for this project will also be investigated.

With some basic information with respect to solvent and catalyst interactions, both individual large particles and fine particulate samples of each coal will be impregnated or ion-exchanged with the catalyst, and the dried sample prepared and observed under the SEM to determine the extent of impregnation and dispersion of the catalyst.

\section{Coal Pretreatment}

Two coals, a lignite and an hvCb, will be selected from the Penn State Sample Bank in consultation with DOE. Each coal will possess high vitrinite and low sulfur contents and ash yields, and will have been thoroughly characterized by proximate and ultimate analyses, maceral and reflectance analyses, as well as major and trace elements.

The principal objective of this work is to explore the influences of catalyst presence, dispersion and chemistry on coal pretreatment. All experiments will be carried out in $25 \mathrm{Ml}$ microautoclave reactors, under $1000 \mathrm{psi}$ (cold) pressure and using a nominal $5 \mathrm{~g}$ of coal and $5 \mathrm{~g}$ of vehicle. The time-temperature regimes will be defined on the basis of results obtained from the catalyst transformation investigations. Temperature-staged liquefaction consists of two distinct steps, the lowtemperature pretreatment and the high-temperature liquefaction reaction. The main focus of this work is on pretreatment, and therefore most of the 
experiments will be carried out in the range of $275^{\circ}-350^{\circ} \mathrm{C}$. In order to assure that the pretreatment stage has been effective in converting the starting coal into an "active coal" intermediate, a limited number of experiments will be performed incorporating the second, high-temperature stage $\left(425^{\circ} \mathrm{C}\right)$ as well. The gas atmosphere will be hydrogen. If tests from the catalyst transformation work are encouraging, additional experiments will be performed in 95:5 $\mathrm{H}_{2}: \mathrm{H}_{2} \mathrm{~S}$ atmospheres.

Experiments will be run without catalyst to obtain baseline data and with each of the four catalyst precursors. The level of catalyst loading will be chosen to ensure that the amount of metal left in the residue is detectable by the planned characterization techniques. Also, catalyst loading will be adjusted so that the same loading on a gram-atom basis is achieved for the iron and molybdenum. Furthermore, the experiments will be run with and without a hydrogen-donor vehicle. It is planned to use phenanthrene as a non-donor vehicle and dihyrophenanthrene as a donor vehicle.

Following liquefaction, a variety of conventional techniques will be used to characterize gaseous, liquid and solid products. Gases will be routinely analyzed by gas chromatography. 0ils and asphaltenes will be routinely analyzed by GC, GC/MS, and ${ }^{1} H$ NMR, and by FTIR and ${ }^{13} \mathrm{C}$ (solution) NMR for selected samples. Selected samples of the solid residue will be characterized by DRIFT, ${ }^{13} \mathrm{C}$ (solid) NMR and optical and electron optical microscopy. 
Evaluation of Impregnated ioals and Residual Materials from Other DOE Programs

Impregnated coals and liquefaction residues will be solicited from DOE and its contractors for microscopic study of materials generated in larger scale experiments than ours, and through other novel approaches to hydrogenation. Samples also will be sought from projects that are developing unique techniques for the impregnation of catalyst into coals for liquefaction. It is expected that many of these samples will come from PETC and the Advanced Research program to assess the degree of catalyst dispersal and to assess the relative extent of hydrogenation and condensation reactions. 
DESCRIPTION OF TECHNICAL PROGRESS

1. THE EFFECT OF PRESWELLING AND CATALYST PRECURSOR ON LIQUEFACTION OF COALS

1.1. Introduction

Liquefacion experiments of solvent-treated and untreated Blind Canyon (DECS-6) and Texas lignite (DECS-1) have been performed using ammonium tetrathiomolybdate (ATTM) and bis (dicarbonylcyclopentadienyl) iron (CPI) as catalyst precursors using temperature-staged conditions $\left(275^{\circ} \mathrm{C}, 30 \mathrm{~min}\right.$; $\left.425^{\circ} \mathrm{C}, 30 \mathrm{~min}\right)$. Solid state ${ }^{13} \mathrm{C}$ NMR analys is was carried out for each coal and for selected residues.

\subsection{Experimental}

1.2.1. The Swelling Procedure and Catalyst Impregnation of Coals

The swelling procedure for the coals for runs without catalyst was given in a previous quarterily technical report (1).

Catalyst impregnation of coals was carried out in the following manner. In the case of ATTM, swelling solvent was added to undried coal (solvent-to-coal ratio is 3 ) and stirred for $6 \mathrm{~h}$ under nitrogen.

Subsequently, the water-methanol solution of ATTM ( $1 \%$ Mo, daf) was added to the coal-solvent mixture (solvent-to-coal ratio is 4 with this addition) and stirred an additional 30 min under nitrogen. Finally, solvent was removed and the sample dried under vacuum at room temperature for swelling with tetrahydrofuran (THF) and at $100^{\circ} \mathrm{C}$ for swelling with pyridine. When tetrabutylammonium hydroxide (TBAH) was used as a swelling reagent, ATTM was dissolved in a $1: 1(\mathrm{w} / \mathrm{w})$ ratio of water-methanol solution of $10 \% \mathrm{TBAH}$. 
Then this solution was mixed with coal and stirred for $6 \mathrm{~h}$ under nitrogen (the ТВAH solution-to-coal (dry basis) ratio is 3 ). Subsequently, the water and methanol in this mixture were removed at room temperature under vacuum.

In the case of CPI, CPI was dissolved in enough methanol, pyridine or THF to give a 3:1 ratio of solvent to coal. The solution was mixed with coal and stirred for $6 \mathrm{~h}$ under nitrogen. After stirring, THF and methanol were removed and the sample dried at room temperature; excess pyridine was removed at room temperature then dried at $100^{\circ} \mathrm{C}$ in vacuum.

Coal-solvent mixtures were stirred continuously by using a magnetic stirrer during removal of excess solvent from the mixture.

\subsubsection{Liquefaction Experiments and Product Work-up}

The details of the liquefaction reactions and sample work-up procedures are given in previous quarterly technical reports $(1,2)$.

THF-insoluble residues were analyzed by solid state ${ }^{13} \mathrm{C}$ NMR. The NMR spectra were recorded on a Chemagnetics M-100 NMR spectrometer by using the cross-polarization and magic-angle spinning (CPMAS) technique.

\subsection{Results and Discussion}

Temperature-staged liquefaction data for preswollen Blind Canyon coal without catalyst were already given in a previous quarterly technical report (1). From this investigation it was found that methanol and THF pretreatment did not improve conversion. Pyridine treatment provided a slight increase in total conversion and formation of oil. TBAH addition 
increased total conversion from $48 \%$ to $58.7 \%$ via higher formation of asphaltenes and lower formation of oil relative to that of unswollen coal. In the current investigation with ATTM, using THF and pyridine as impregnation solvents, there was a slight increase in total conversion from $85.1 \%$ to $88 \%$ and $90.3 \%$, respectively, relative to that of unswollen coal (Table 1.1). The product slate also shifted to lighter fractions. Formation of oil increased from $33.9 \%$ to $41.9 \%$ with THF and to $43.0 \%$ with pyridine. The fact that hydrogen absorption increased to $24.4 \mathrm{mg}$ per gram coal (daf) with pyridine $(21.6 \mathrm{mg}$ for without unswollen coal) suggests that more catalyst-coal surface contact was ensured using pyridine as an impregnation solvent. However, TBAH addition was detrimental for liquefaction of this coal with ATTM. Addition of TBAH decreased total conversion and formation of $0 i 1$ and increased formation of asphaltenes, probably due to promoting retrogressive reactions.

NMR data and $f_{a}$ values of Blind Canyon coal and liquefaction residues are given in Figures 1.1-1.4 and Table 1.2. Following liquefaction, the intensity of the aliphatic region (0-60 ppm) was decreased with respect to the original coal. The shoulder peak at $140 \mathrm{ppm}$ (catechol-like C) disappeared after liquefaction reactions with or without catalyst. The intensity of the shoulder peak at $153 \mathrm{ppm}$ (phenolic or aromatic ether C) also was diminished. However, the loss of the peak was more noticeable with ATTM as compared to the no catalyst condition. The $f_{a}$ value of the residue was less for the molybdenum sulfide catalyzed reaction than that of the residue from the thermal run $(0.891$ vs. 0.850$)$. When pyridine was used 
Table 1.1. Effect of preswelling on liquefaction of Blind Canyon (DECS-6) with ATTM $\left(275^{\circ} \mathrm{C}, 30 \mathrm{~min} ; 425^{\circ} \mathrm{C}, 30 \mathrm{~min}\right)$.

\begin{tabular}{cccccccc}
\hline & \multicolumn{6}{c}{ Conversion $\%$ (daf) } \\
\cline { 3 - 8 } Solvent & $\begin{array}{c}\mathrm{H}_{2} \text { Abs. } \\
(\mathrm{mg})^{\mathrm{a}}\end{array}$ & Total & P.asph. & Asph. & $0 \mathrm{il}$ & $\mathrm{CO}_{\mathrm{x}}$ & $\mathrm{C}_{1} \mathrm{C}_{5}$ \\
\hline \hline Water & 21.6 & 85.1 & 14.7 & 32.5 & 33.9 & 1.9 & 2.1 \\
THF & 22.2 & 88.0 & 13.4 & 28.1 & 41.9 & 1.7 & 2.9 \\
Pyridine & 24.4 & 90.3 & 9.4 & 33.7 & 43.0 & 0.8 & 3.3 \\
TBAH $^{\mathrm{b}}$ & 22.4 & 81.7 & 9.5 & 45.9 & 26.3 & 2.6 & 4.0
\end{tabular}

a Per gram of dry-ash free coal

b Hydrocarbon carbon content of yield corrected using the gas analys is result of TBAH obtained by hydrogenating TBAH at liquefaction condition without coal and catalyst.

Table 1.2. $f_{a}$ values of THF-insoluble residues of $B 1$ ind Canyon coal (DECS-6) with or without ATTM

\begin{tabular}{c||cccc} 
Solvent & -- & None & None & pyridine \\
Catalyst & --- & None & Yes & Yes \\
$f_{a}$ & $0.598^{*}$ & 0.891 & 0.850 & 0.871
\end{tabular}

*Parent coal

as the impregnation solvent, the $f_{a}$ value of the residue increased slightly compared with that of the residue from the unswollen coal.

For temperature-staged reaction of CPI with Blind Canyon coal (DECS-

1), an $\mathrm{H}_{2} \mathrm{~S}: \mathrm{H}_{2}$ atmosphere was superior to $\mathrm{H}_{2}(69.2 \%$ vs. 76.0$)$ presumably resulting from sulfiding iron to the active pyrrhotite catalyst (Table 1.3). Using THF as the impregnation solvent slightly increased total conversion of Blind Canyon coal via higher formation of asphaltenes. 


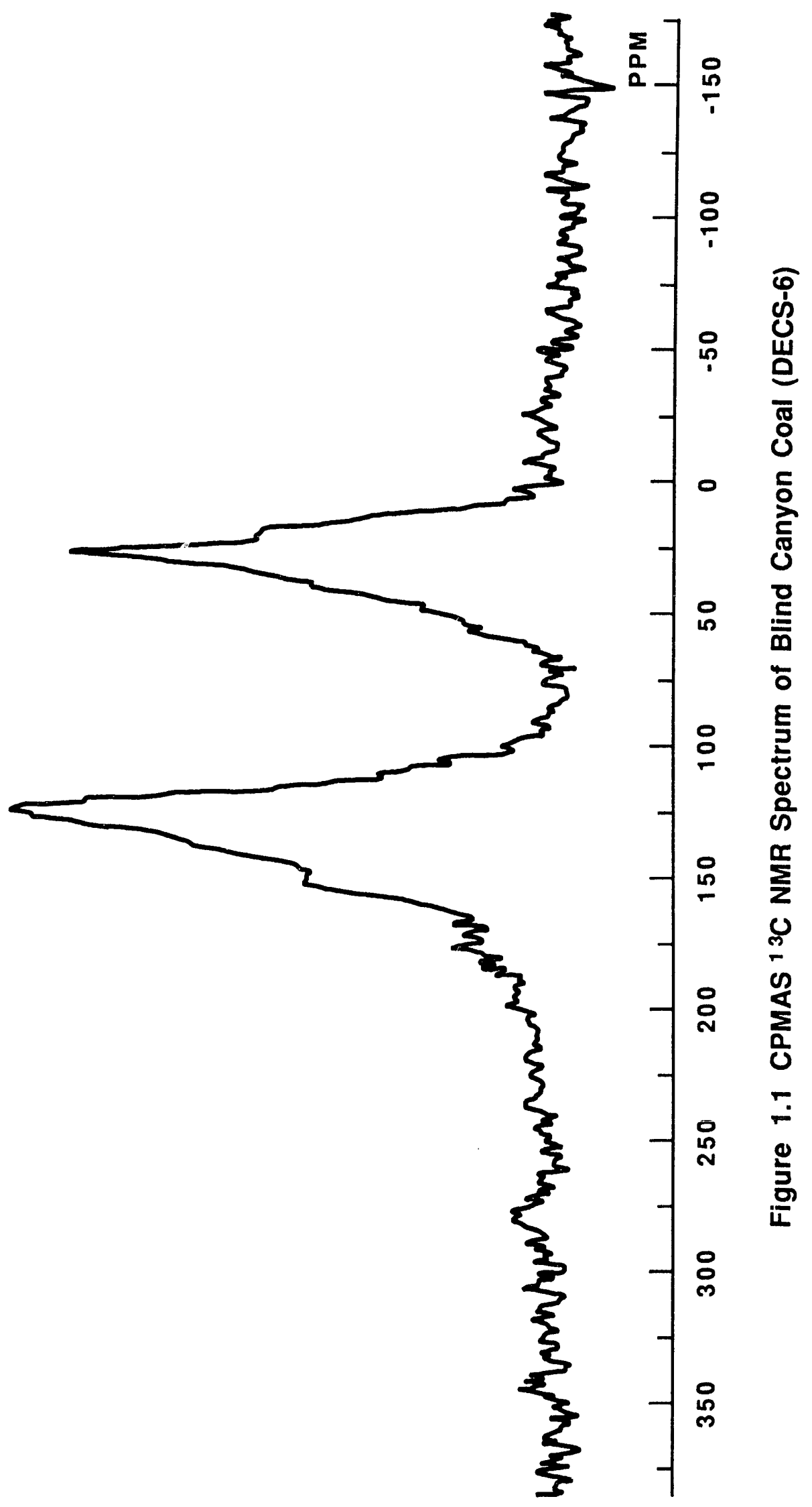




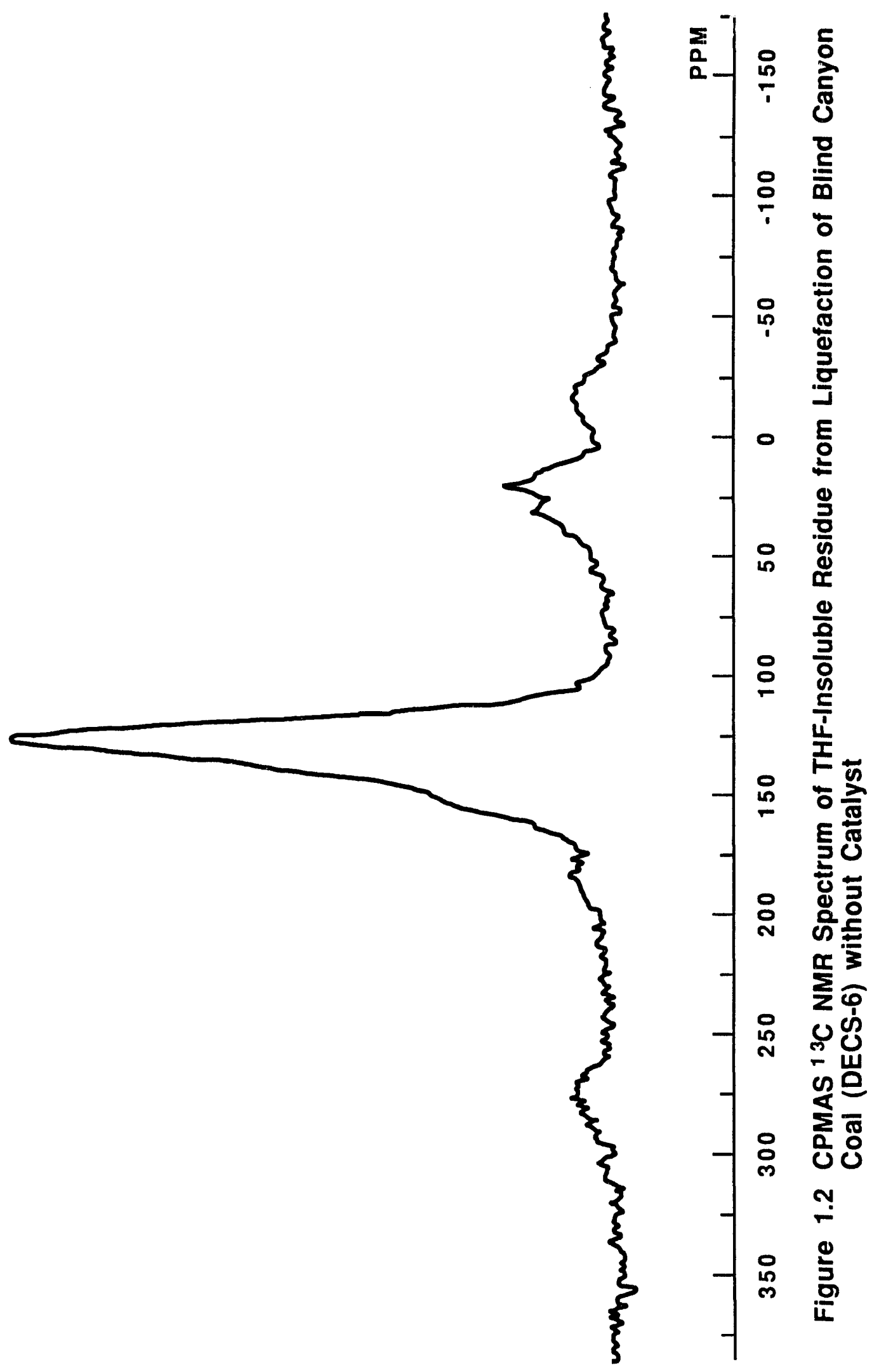




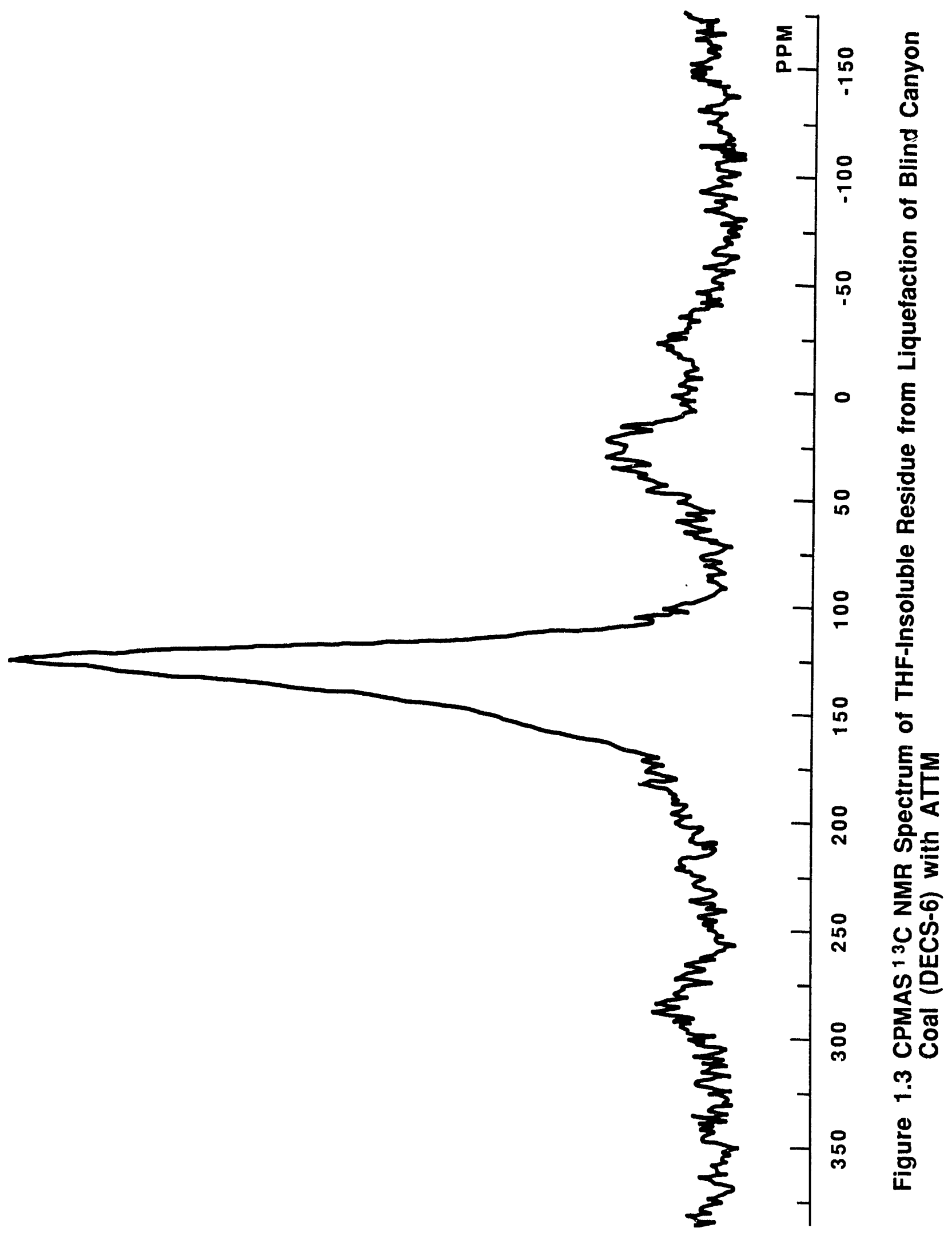




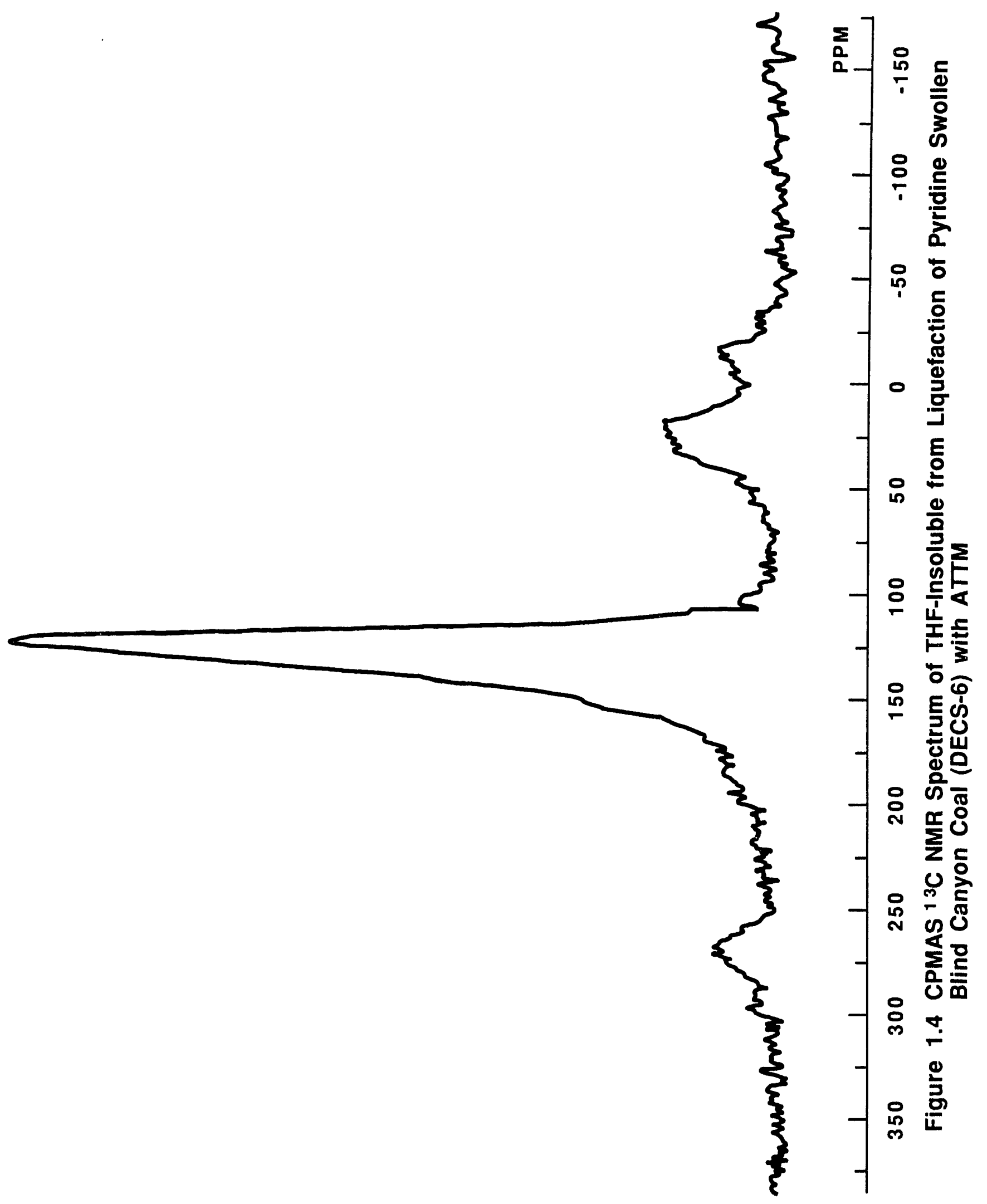


However, when pyridine was used as the impregnation solvent, total conversion and hydrogen consumption decreased relative to that of the reaction in which methanol was used as the impregnation solvent in $\mathrm{H}_{2} \mathrm{~S}: \mathrm{H}_{2}$.

Table 1.3. Effect of preswelling on liquefaction of Blind Canyon (DECS-6) with CPI in $\mathrm{H}_{2} \mathrm{~S}: \mathrm{H}_{2}\left(275^{\circ} \mathrm{C}, 30 \mathrm{~min} ; 425^{\circ} \mathrm{C}, 30 \mathrm{~min}\right)$.

\begin{tabular}{cccccccc}
\hline & & \multicolumn{6}{c}{ Conversion \% (daf) } \\
\cline { 3 - 8 } Solvent & $\begin{array}{c}\mathrm{H}_{2} \text { Abs. } \\
(\mathrm{mg})^{\mathrm{a}}\end{array}$ & Total & P.asph. & Asph. & $0 \mathrm{il}$ & $\mathrm{CO}_{x}{ }^{\mathrm{d}}$ & $\mathrm{C}_{2}-\mathrm{C}_{5}$ \\
\hline \hline Meth. $^{\mathrm{C}}$ & 13.3 & 69.2 & 17.7 & 18.3 & 26.7 & 3.3 & 3.2 \\
Meth. & 16.5 & 76.0 & 16.2 & 20.6 & 31.9 & 3.8 & 3.5 \\
THF & 18.0 & 80.0 & 17.0 & 25.2 & 28.9 & 4.8 & 4.1 \\
Pyridine 14.7 & 69.1 & 8.8 & 25.5 & 27.4 & 3.3 & 4.1 \\
a As defined in Table 1.1. \\
c Reaction was performed in hydrogen \\
d Corrected from Co content of CPI
\end{tabular}

It was calculated from the increase in nitrogen content of pyridine-treated coals compared to untreated coals, that pyridine content varied between 2$4 \%$ for the $B 1$ ind Canyon and $6-10 \%$ for the Texas lignite. Pyridine-treated coals are corrected for pyridine content for the calculation of yields. From these results, it appears that for some reason pyridine may interfere with the activity of the CPI catalyst.

In the case of Texas lignite (DECS-1), pyridine and TBAH treatments improved conversion of the coal significantly (Table 1.4). Pyridine treatment increased total conversion via higher formation of oil $(29.2 \%$ vs. $21.2 \%$ ). TBAH was even more positive for total conversion of the Texas 
lignite $(72.1 \%)$ via higher formation of asphaltenes. It should be mentioned that the total conversion value obtained with TBAH treatment was nearly equal to the results obtained with the other iron-based catalyst (iron sulfate and iron pentacarbonyl) for this coal. Lignites contain various acidic sites, such as $-\mathrm{COOH}$ and $-\mathrm{OH}$ functional groups. Nitrogencontaining basic compounds can neutralize these acidic sites and TBAH also

Table 1.4. Effect of solvent swelling on liquefaction of Texas lignite (DECS- $1,275^{\circ} \mathrm{C}, 30 \mathrm{~min} ; 425^{\circ} \mathrm{C}, 30 \mathrm{~min}$ ). Conversion \% (daf)

\begin{tabular}{|c|c|c|c|c|c|c|c|}
\hline Solvent & $\begin{array}{l}\mathrm{H}_{2} \text { Abs. } \\
(\mathrm{mg})^{\mathrm{a}}\end{array}$ & Total & P.asph. & Asph. & $0 i 1$ & $\mathrm{COx}$ & $C_{1}-C_{5}$ \\
\hline None & 6.1 & 53.1 & 8.2 & 10.9 & 21.2 & 9.9 & 2.9 \\
\hline Pyridine & 7.3 & 60.1 & 9.2 & 9.7 & 29.5 & 9.3 & 2.4 \\
\hline TBAH $^{\mathrm{D}}$ & 9.7 & 72.1 & 10.9 & 24.3 & 25.8 & 6.9 & 4.2 \\
\hline
\end{tabular}

${ }^{a, b}$ As defined in Table 1.1

might alkylate coal in situ (3). It is claimed that alkylation of coals may be beneficial for coal liquefaction $(4,5)$. It is estimated that TBAH transforms to amines (mainly tributylamine) during coal liquefaction. Amines are good promoters for coal liquefaction (6-8). All of these effects may combine for improved liquefaction. With ATTM, solvent treatment provided higher conversion by increasing formation of asphaltenes (Table 1.5). Pyridine and TBAH treatment showed a similar effect for liquefaction of Texas lignite. 
NMR data and $f_{a}$ values for the Texas lignite and its liquefaction residues are given in Figures 1.5-1.9 and Table 1.6. Aromaticity of this coal was less than that of the Blind Canyon (compare Figure 1.1 with 1.5). The concentrations of etheric or phenolic aromatic C (152 ppm), carboxylic C (175-180 ppm) and ketone or aldehyde C (208 ppm) are more abundant than in Blind Canyon coal. As with the Blind Canyon coal, the intensity of the aliphatic region (0-60 ppm) diminishes, the $f_{a}$ value increases $(0.850 \mathrm{vs}$. 0.438) and ketone and carboxylic carbon almost disappear compared with that of the parent coal

Table 1.5. Effect of solvent swelling on liquefaction of Texas lignite (DECS-1) with ATTM $\left(275^{\circ} \mathrm{C}, 30 \mathrm{~min} ; 425^{\circ} \mathrm{C}, 30 \mathrm{~min}\right)$.

\begin{tabular}{cccccccc}
\hline & & \multicolumn{7}{c}{ Conversion $\%$ (daf) } \\
\cline { 3 - 7 } Solvent & $\begin{array}{c}\mathrm{H}_{2} \text { Abs. } \\
(\mathrm{mg})^{\mathrm{a}}\end{array}$ & Total & P.asph. & Asph. & $0 i 1$ & $\mathrm{CO}_{\times}$ & $\mathrm{C}_{1}-\mathrm{C}_{5}$ \\
\hline \hline Water & 24.3 & 78.9 & 10.6 & 19.3 & 36.4 & 10.3 & 2.3 \\
Pyridine & 28.4 & 88.8 & 10.9 & 30.1 & 37.4 & 5.6 & 4.3 \\
TBAH $^{\mathrm{b}}$ & 25.4 & 88.9 & 8.9 & 35.6 & 34.6 & 6.3 & 4.2
\end{tabular}

a,b As defined in Table 1.1

Table 1.6. $f_{a}$ values of THF-insoluble residues of $B$ lind Canyon coal (DECS- $i$ ) with or without ATTM

\begin{tabular}{c||ccccc} 
Solvent & -- & None & None & pyridine & TBAH \\
Catalyst & --- & None & Yes & Yes & ATTM \\
$f_{a}$ & $0.598^{*}$ & 0.891 & 0.850 & 0.881 & 0.896
\end{tabular}

*Parent coal 


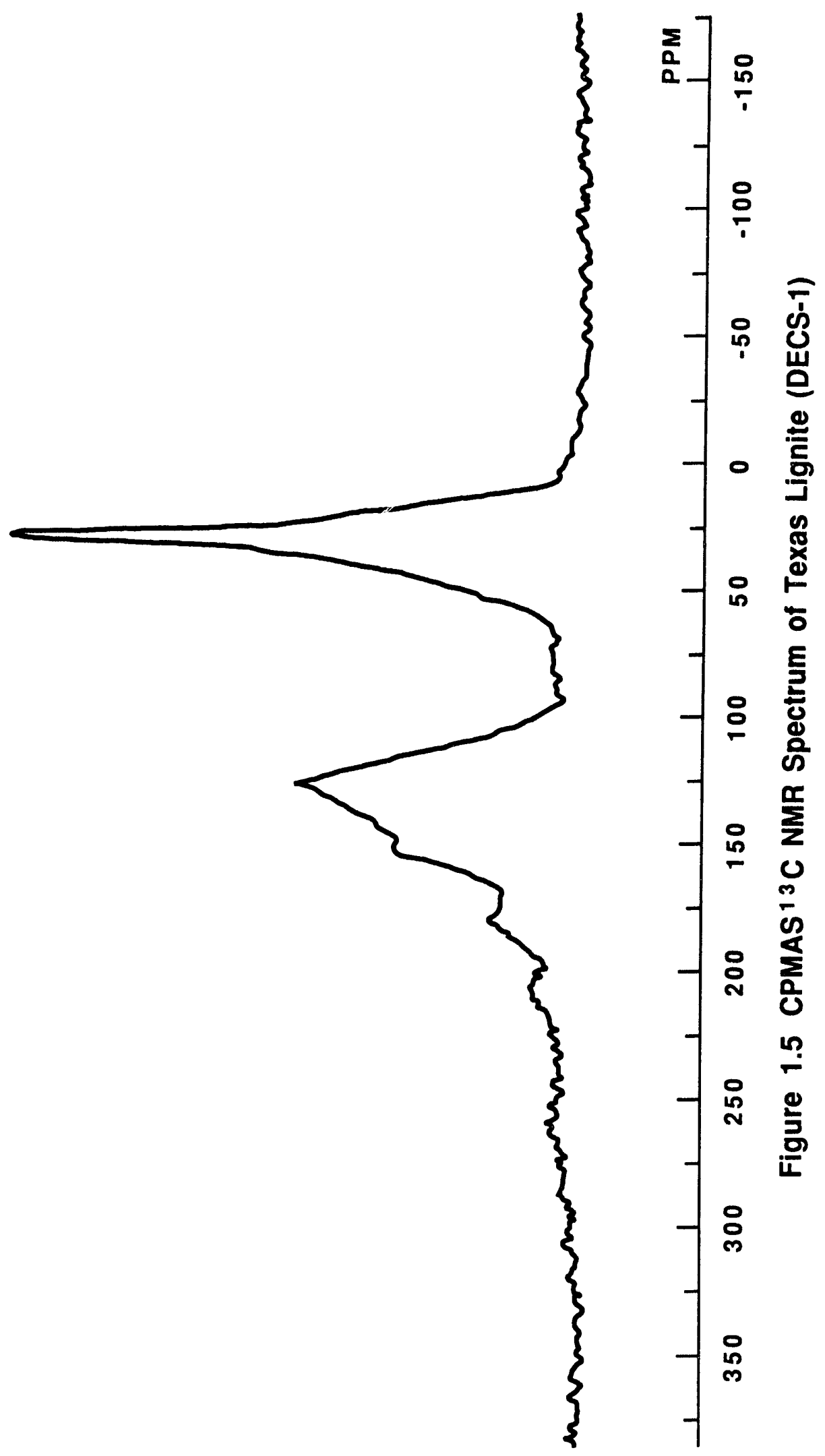




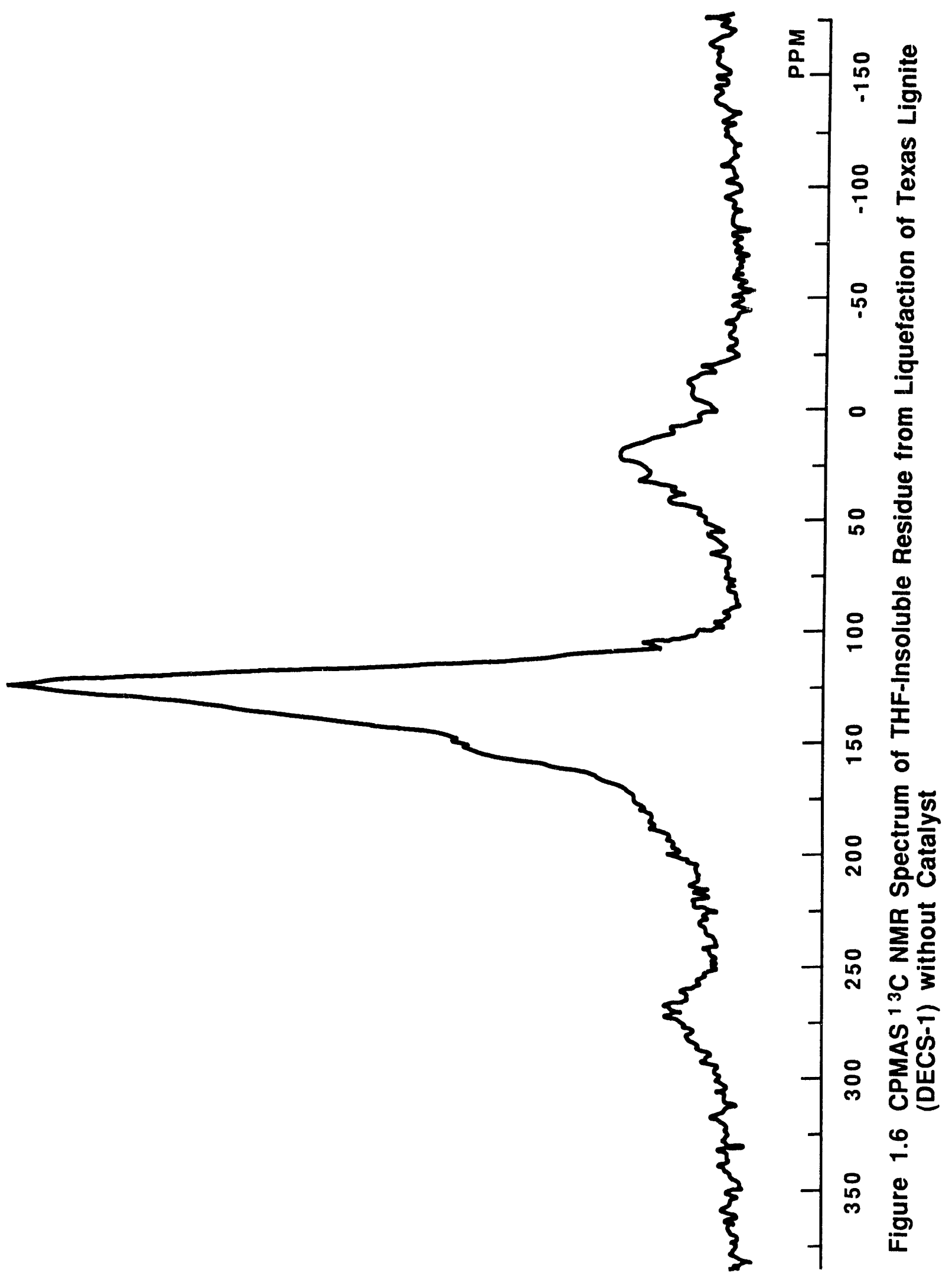




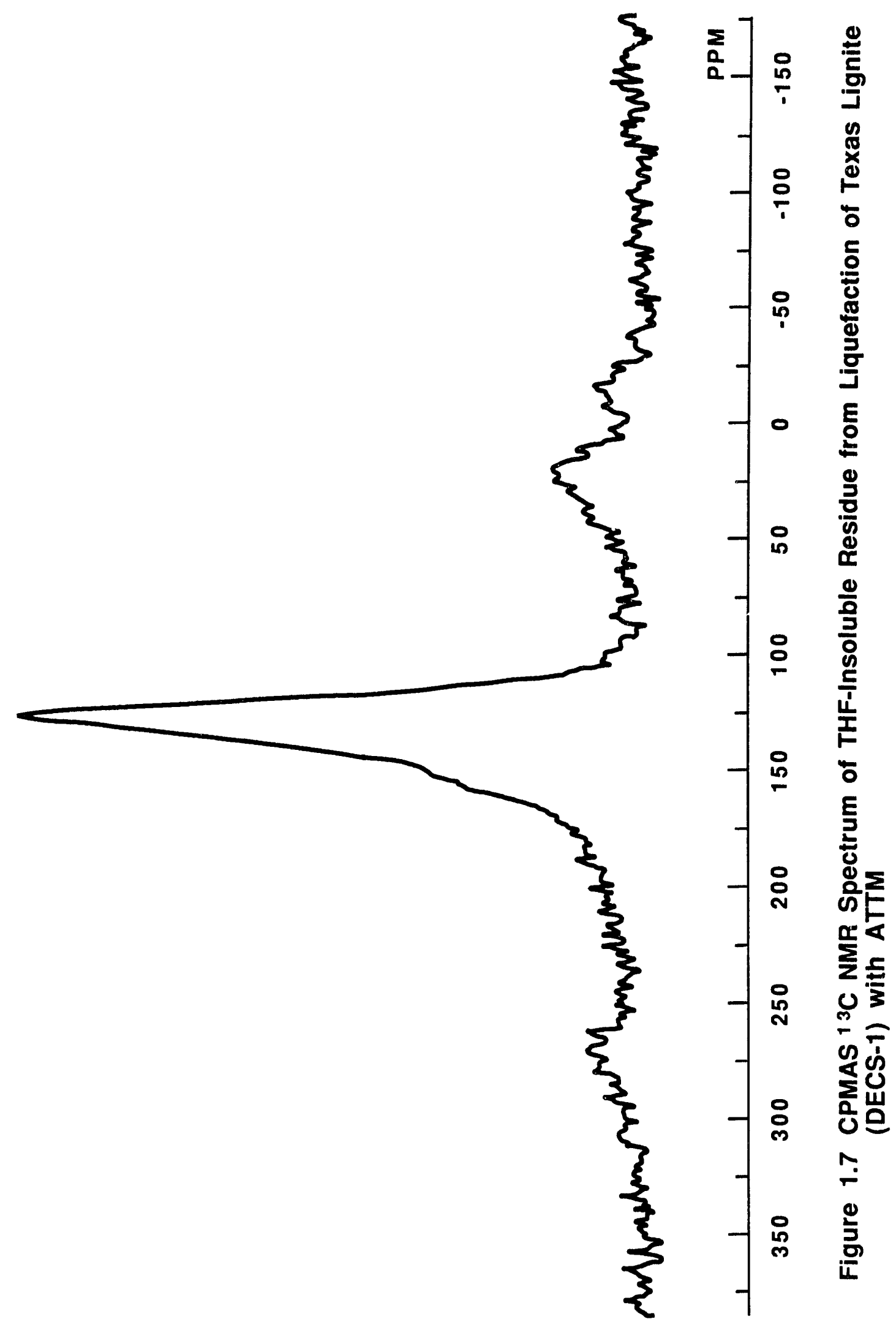




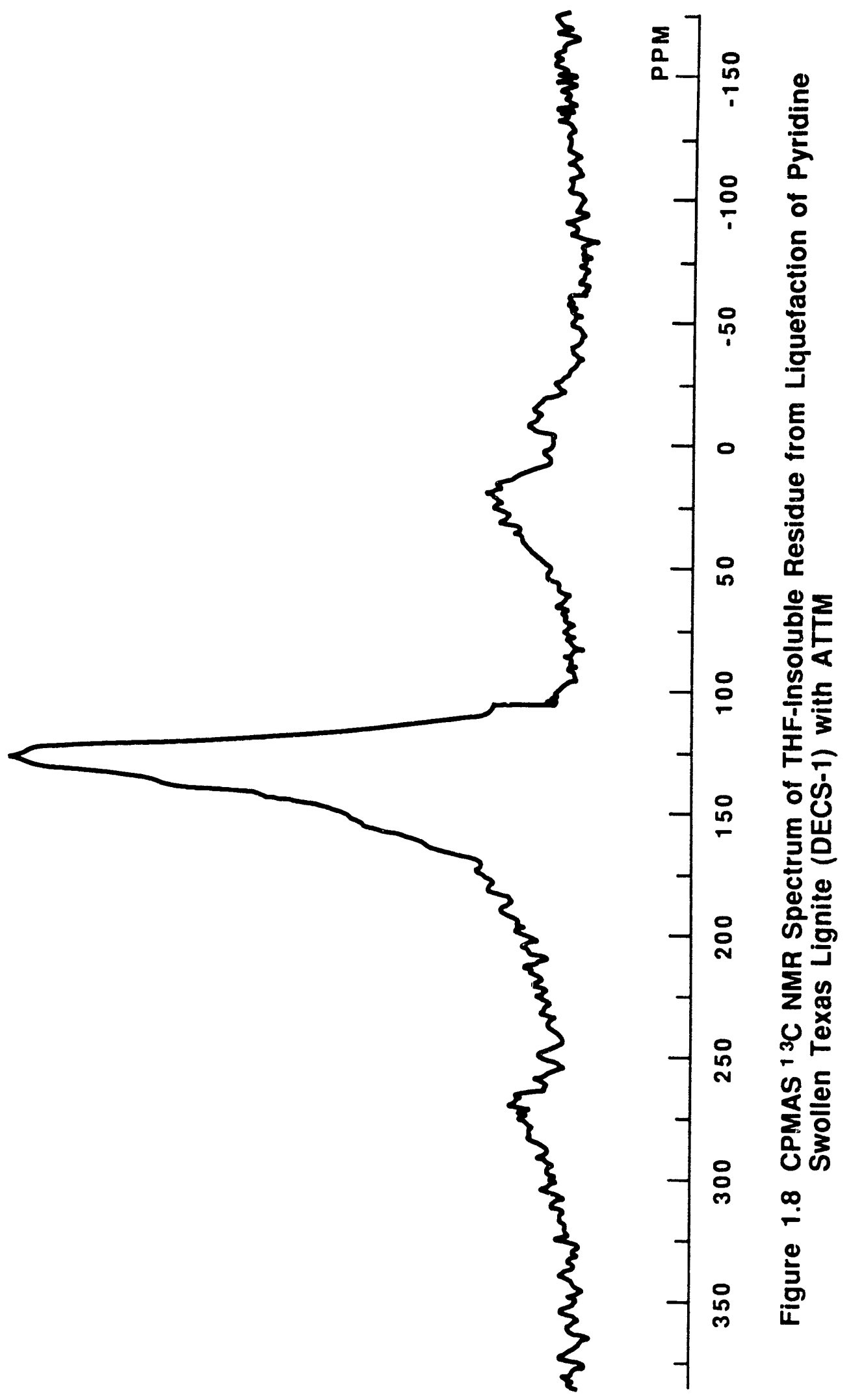




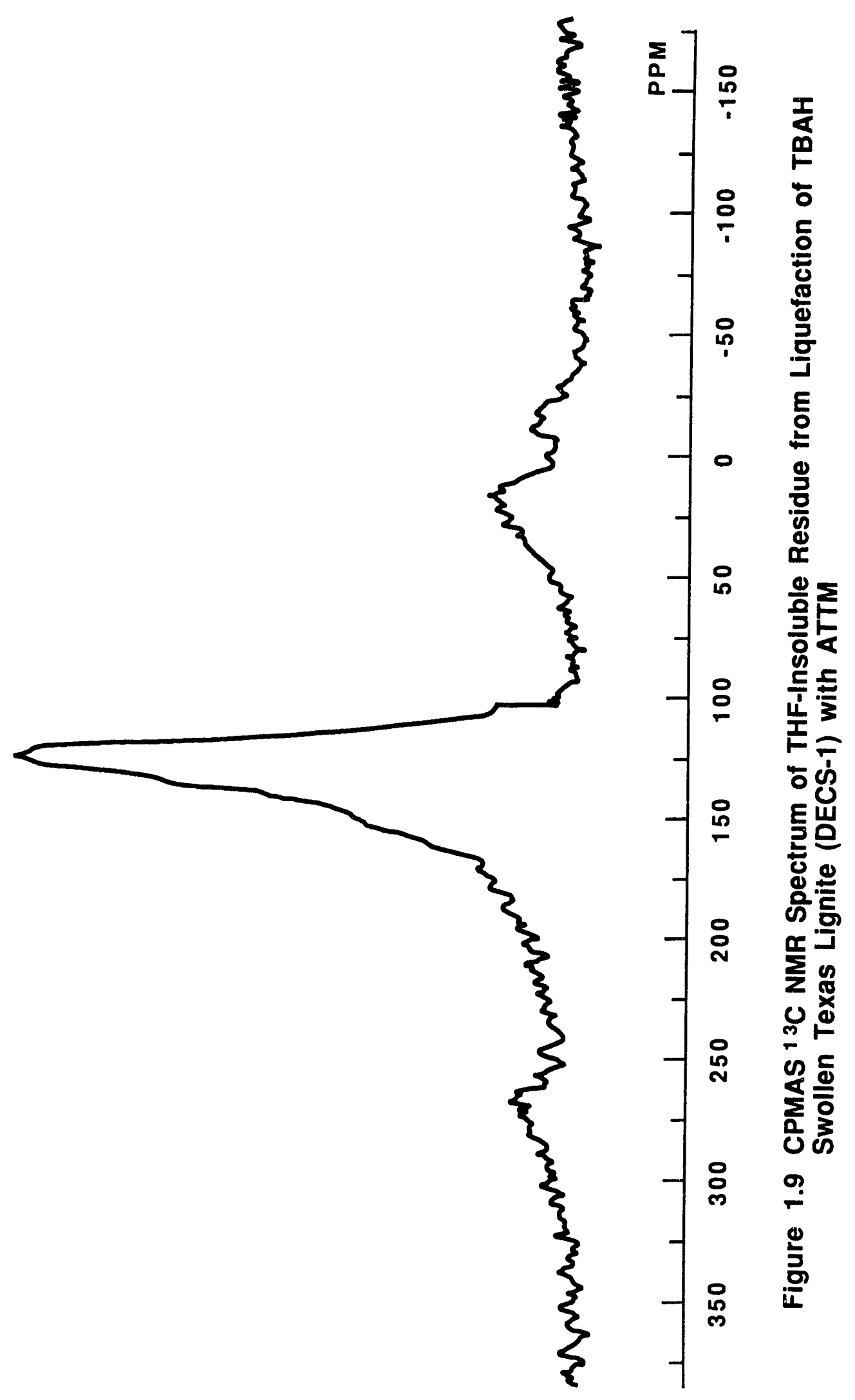


regardless of whether liquefaction was performed with or without catalyst. Solvent treatment increased the $f_{a}$ value to 0.881 for the pyridine-treated coal and 0.896 for the TBAH-treated coal. Relative peak intensity ratio of phenolic-carbon to aromatic C (maximum of peak at 127-130 ppm) decreased significantly as a result of liquefaction. This ratio did not differ significantly when the ATTM catalyst or solvent swelling was employed.

With CPI (Table 1.7), pyridine treatment did not improve conversion of Texas lignite beyond that of methanol pretreatment, probably due to the reasons explained for the $B l$ ind Canyon coal.

Table 1.7. Effect of solvent swelling on liquefaction of Texas lignite (DECS-1) with CPI in $\mathrm{H}_{2} \mathrm{~S}: \mathrm{H}_{2}\left(275^{\circ} \mathrm{C}, 30 \mathrm{~min} ; 425^{\circ} \mathrm{C}, 30 \mathrm{~min}\right)$

Conversion $\%$ (daf)

\begin{tabular}{cccccccc} 
Solvent & $\begin{array}{c}\mathrm{H}_{2} \text { Abs. } \\
(\mathrm{mg})^{\mathrm{a}}\end{array}$ & Total & P.asph. & Asph. & $0 i 1$ & $\mathrm{CO}_{\mathrm{x}}^{\mathrm{d}}$ & $\mathrm{C}_{1} \mathrm{C}_{5}$ \\
\hline \hline Meth. $^{\mathrm{C}}$ & 15.3 & 63.7 & 11.2 & 15.6 & 22.0 & 11.6 & 3.3 \\
Meth. & 18.7 & 74.3 & 9.6 & 23.2 & 30.2 & 8.06 & 3.4 \\
Pyridine & 20.5 & 73.6 & 6.2 & 24.0 & 30.2 & 8.7 & 4.5
\end{tabular}

$a, b, c, d$ As defined in Table 1.1 and 1.3

\subsection{Conclusions}

Liquefaction results and NMR data suggest that molybdenum sulfide enhances dissolution of coals contributing to a higher formation of asphaltenes and $0 \mathrm{il}$. THF and pyridine treatment of Blind Canyon increased formation of $0 i 1$ in the presence of ATTM. However, TBAH addition to the reaction medium was detrimental for liquefaction of this coal. TBAH and 
pyridine treatment significantly promoted the liquefaction of Texas lignite with or without ATTM.

Using pyridine as a swelling reagent with the CPI catalyst was found to be ineffective and perhaps interferes with the activity of the catalyst. 
References

1. Davis, A., Schobert, H.H., Mitchel1, G.D. and Artok, L. (1991). Catalyst Dispersion and Activity Under Conditions of Temperature Staged Liquefaction, DOE Technical Report for the Period January to March 1991, No. DOE-PC-89877-6.

2. Davis, A., Schobert, H.H., Mitchel1, G.D. and Artok, L. (1990). Catalyst Dispersion and Activity Under Conditions of Temperature Staged Liquefaction, DOE Technical Report for the Period July to September 1990, No. DOE-PC-89877-4.

3. Anderson, K.B. and Winans, R.E., (1991). Preprints Div. Fuel Chem., Am. Chem. Soc., 36(2), 765.

4. Baldwin, R.M., Kennar, D.R., Nguanprasert, 0. and Miller, R.L., (1991). Fuel, 70, 429.

5. Schlosberg, R.H., Nevael, R.C., Moa, P.S. and Gorbaty, M.L., (1980). Fuel, 59, 45 .

6. Kazimi, F., Chen, W.Y., Whitney, R.R., Zimny, B., (1985). Preprints Div. Fuel Chem., Am. Chem. Soc., 30(4), 402.

7. Tagaya, H., Sugai, J., Onuki, M. and Chiba, K., (1987). Energy \& Fuel, $1,397$.

8. Miller, R.L., Baldwin, R.M. and Kennar, D.R., (1990), Preprints Div. Fuel Chem., Am. Chem. Soc., 35(1), 9. 


\section{CATALYST DISPERSION ON COALS}

\subsection{Introduction}

As continued from a previous quarterly progress report (1), particulate samples of the Blind Canyon (DECS-6) and Texas lignite (DECS-1) coals which were preswollen in various reagents and then impregnated with ATTM, have been characterized using SEM - EDS and electron microprobe (EP) analyses to determine the degree of dispersion and/or impregnation of the catalyst into coal surfaces. Particulate samples were prepared following the same technique used for liquefaction except the samples were not thermally reacted. Characterization of these sample should provide some indication of the effectiveness of the impregnation procedure.

\subsection{Experimental}

As discussed in previous quarterly reports $(1,2),-60$ mesh coal (DECS6 and 1) was dried at $100^{\circ} \mathrm{C}$ in vacuum, mixed with a swelling reagent to give a solvent-to-coal ratio of $3: 1(\mathrm{v} / \mathrm{w})$ and stirred for $6 \mathrm{~h}$ under nitrogen. Swelling reagents used in this part of the study were methanol, pyridine and THF. Solvents were removed by evaporation at room temperature in vacuum for methanol and THF and at $100^{\circ} \mathrm{C}$ for pyridine. An aqueous solution of ATTM was added to each coal sample (1.0 wt.\% Mo) in the manner described in a previous report (1). The dry, particulate coal samples impregnated with ATTM were then prepared for characterization using the SEM and electron microprobe. Samples were carefully (gently) split to about $0.6 \mathrm{~g}$ using a micro-riffler and a small subsample mounted on a pedestal for 
SEM imaging using double-sided tape. For the electron microprobe, samples were dispersed on the pedestal in a cold-setting epoxy resin to eliminate charging problems.

Particulate samples were prepared for observation under the SEM by coating each with a thin layer of gold, whereas those for EP analysis were coated with carbon. All samples were coated at the same time to ensure an identical coating thickness. An ISI-SX-40A SEM having a Kevex energy dispersive spectrometer (EDS) was used for imaging and for the qualitative analys is of elements greater in atomic number than sodium.

An ETEC automated electron microprobe analyzer was employed for quantitative analyses. The PET (Pentaerythritol) crystal spectrometer was used for sulfur and molybdenum analysis, whereas other elements were monitored with an attached EDS system. Spectrometer wavelengths were calibrated using pyrite $\left(\mathrm{FeS}_{2}\right)$ as a standard for sulfur and $99.95 \%$ pure molybdenum metal for the molybdenum. The accelerating voltage was set at $15 \mathrm{keV}$ and the data were reduced by the ZAF method using an internal software package (MAGIC). The $S_{k \alpha}(5.392 \AA)$ peak was used for sulfur, while the $\mathrm{Mo}_{L \alpha}(5.407 \AA)$ peak was used for molybdenum.

\subsection{Results and Discussion}

Particle mounts of an unswollen Blind Canyon sample impregnated with ATTM were evaluated using the SEM in a similar manner as that of the Texas lignite reported previously (1). The whole sample was scanned and individual particles tested at random for the presents of sulfur and 
molybdenum peaks using the EDS system. This procedure required approximately $1 \mathrm{~h}$ per sample and must be considered qualitative at best. As demonstrated in Figure 2.1, the X-ray energies of molybdenum, sulfur and gold (coating material) overlap between about $2.0-2.5 \mathrm{keV}$. Therefore, some interpretative difficulty arises as to whether ATTM may be present at any given test point. However, the presence of gold and its relative intensity may be established by the $A u_{L \alpha}$ peak at $\sim 9.7 \mathrm{keV}$.

Figure 2.2 demonstrates the effective use of the EDS system where several X-ray energy spectra were collected from different areas of a single coal particle shown in the accompanying SEM micrograph. At the bottom of each SEM micrograph the numbers indicate the electron beam operating voltage, total magnification, number of microns represented by the white bar and the photograph number. The particle shown in Figure 2.2 is from a Blind Canyon sample that was impregnated with ATTM, but was not preswollen with solvent. Area and spectrum \#1 shows a relatively weak gold peak, suggesting that no ATTM may be present at that site. However, for area and spectrum \#2 not only was there a stronger gold peak, but the lower energy peak near $2.0 \mathrm{keV}$ was found to be proportionally much higher, thus implying that Mo and/or $S$ may be contributing $X$-ray energies. In general for this sample, much of the ATTM appeared to be scattered as small discrete particles across the coal surface much as was shown for the Texas lignite sample (1).

A similar SEM evaluation was conducted for Blind Canyon samples that were first swollen in methanol, pyridine and THF before being impregnated 

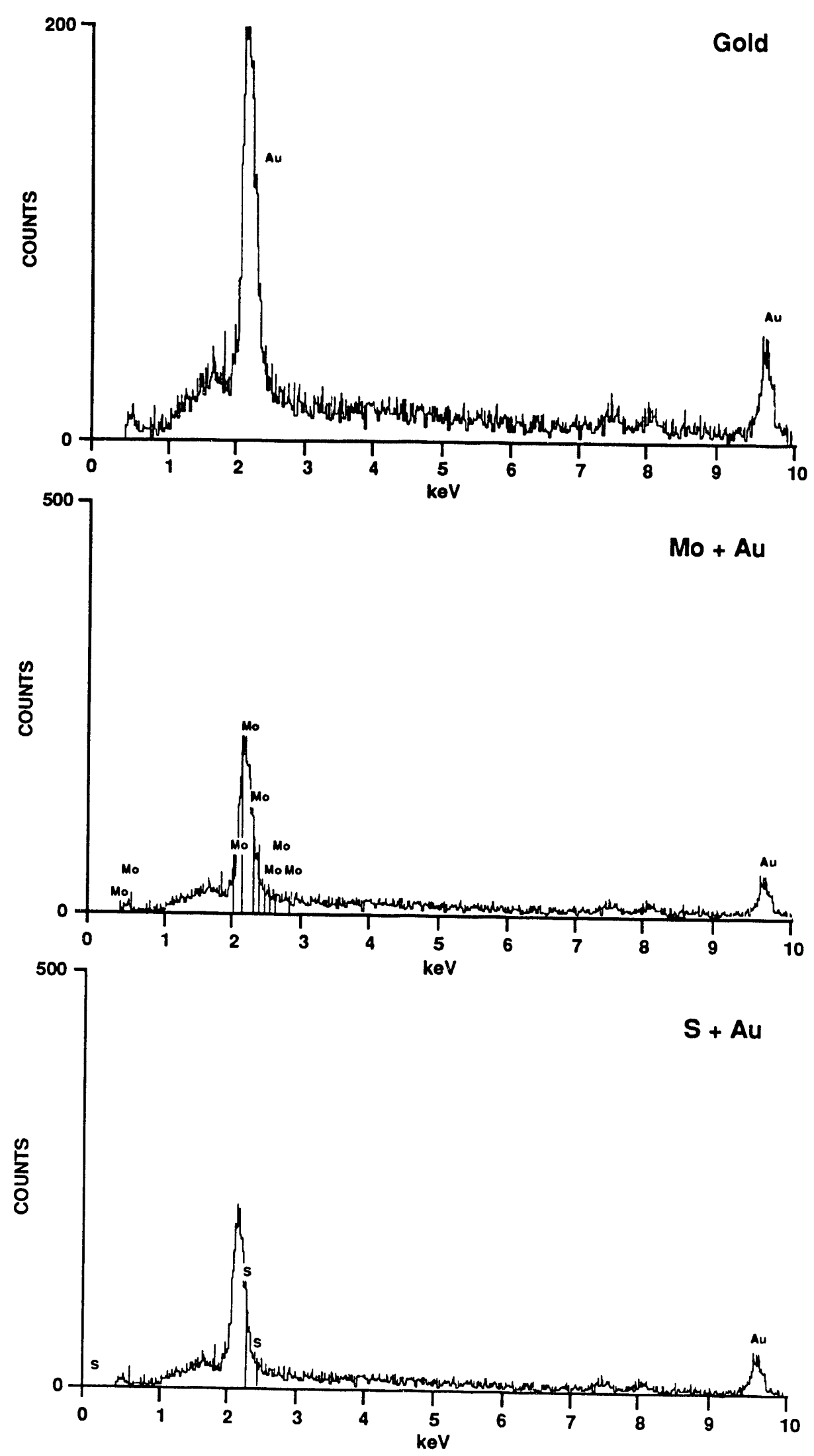

Figure 2.1 X-Ray Counts Accumulated over $100 \mathrm{~s}$ Showing the Location and Overlap of Gold, Molybdenum and Sulfur Peaks in Unswollen Blind Canyon Sample
Following Impregnation with ATTM 


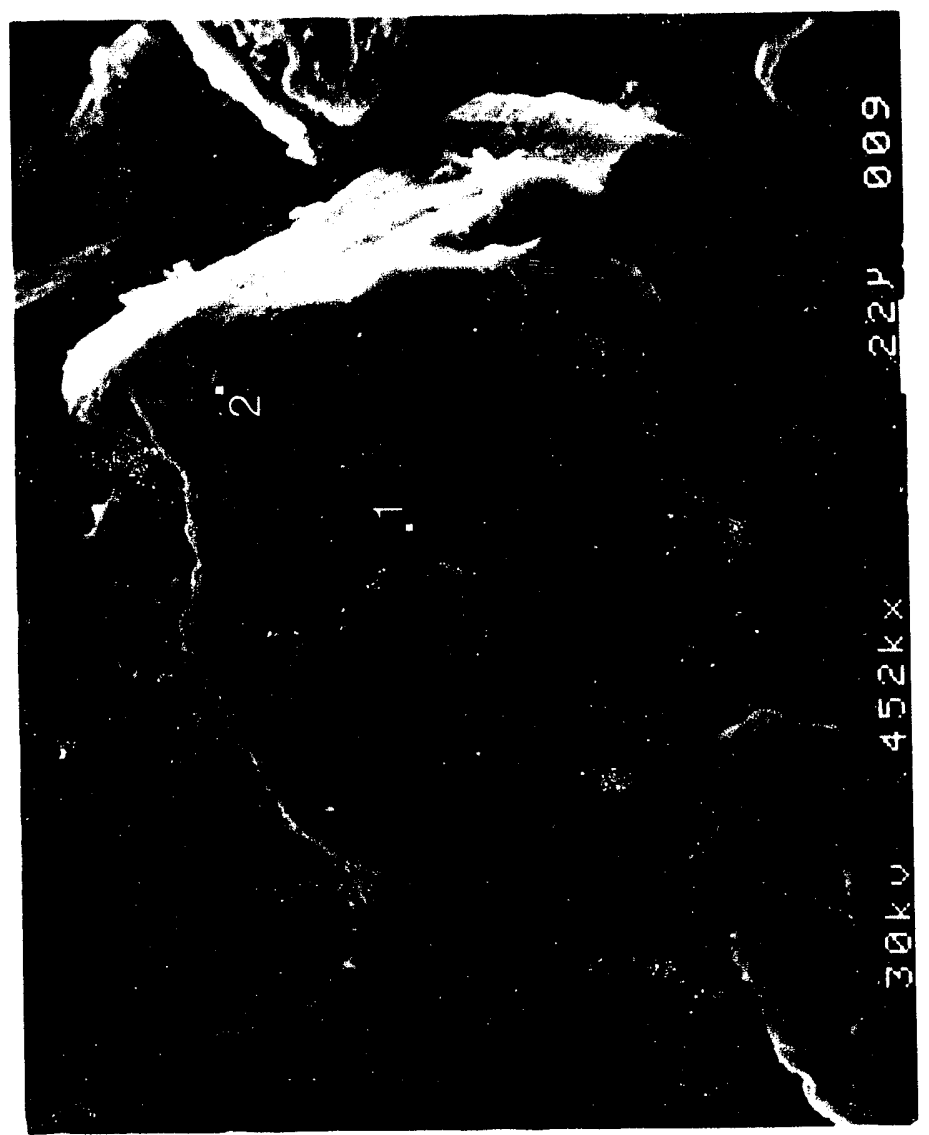

응

ํํํ

흘
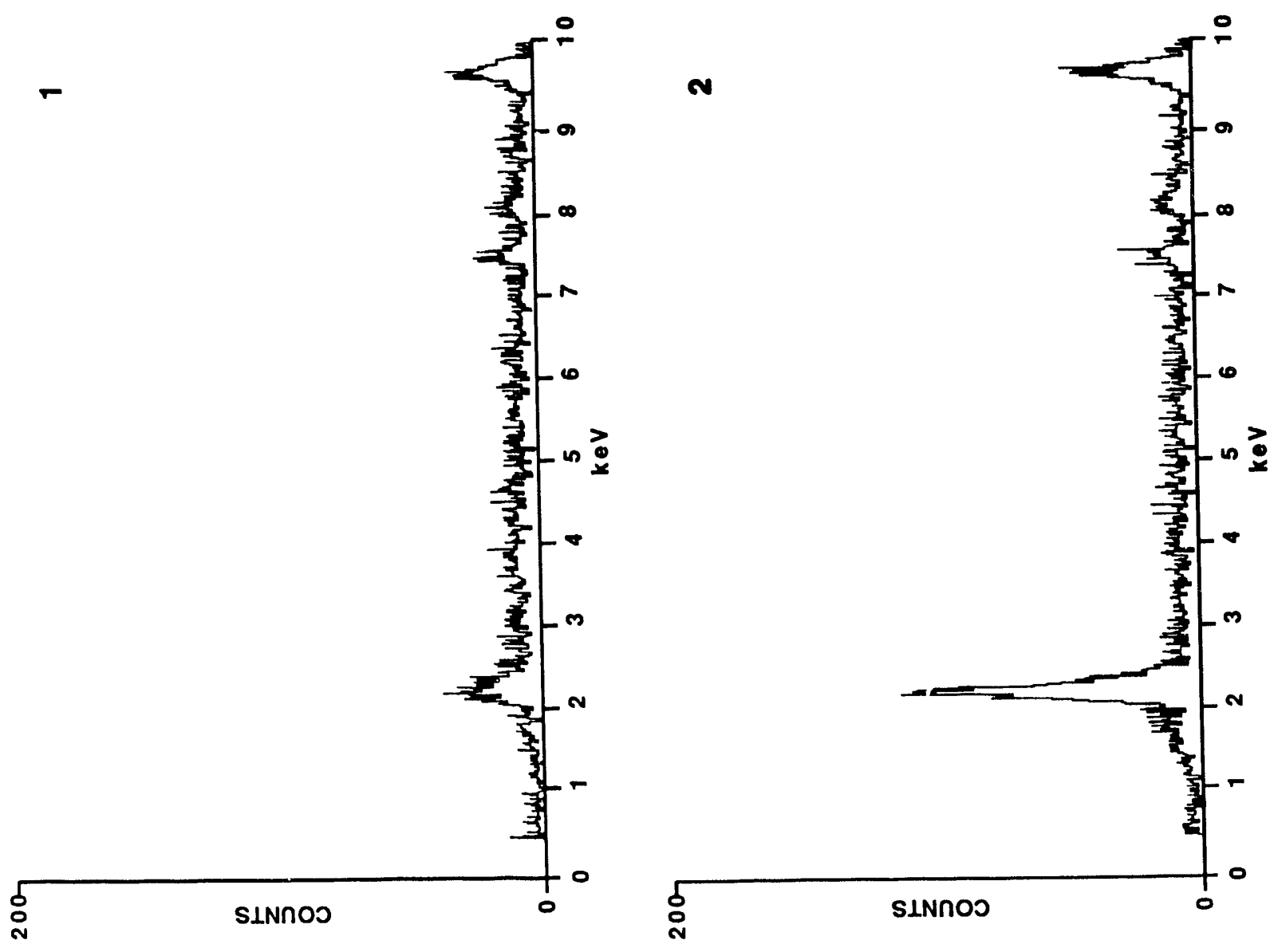

ᄃ

总 3

록

잉

뭉

<

起 o 0. > 赵 丈 으를 พั

온 


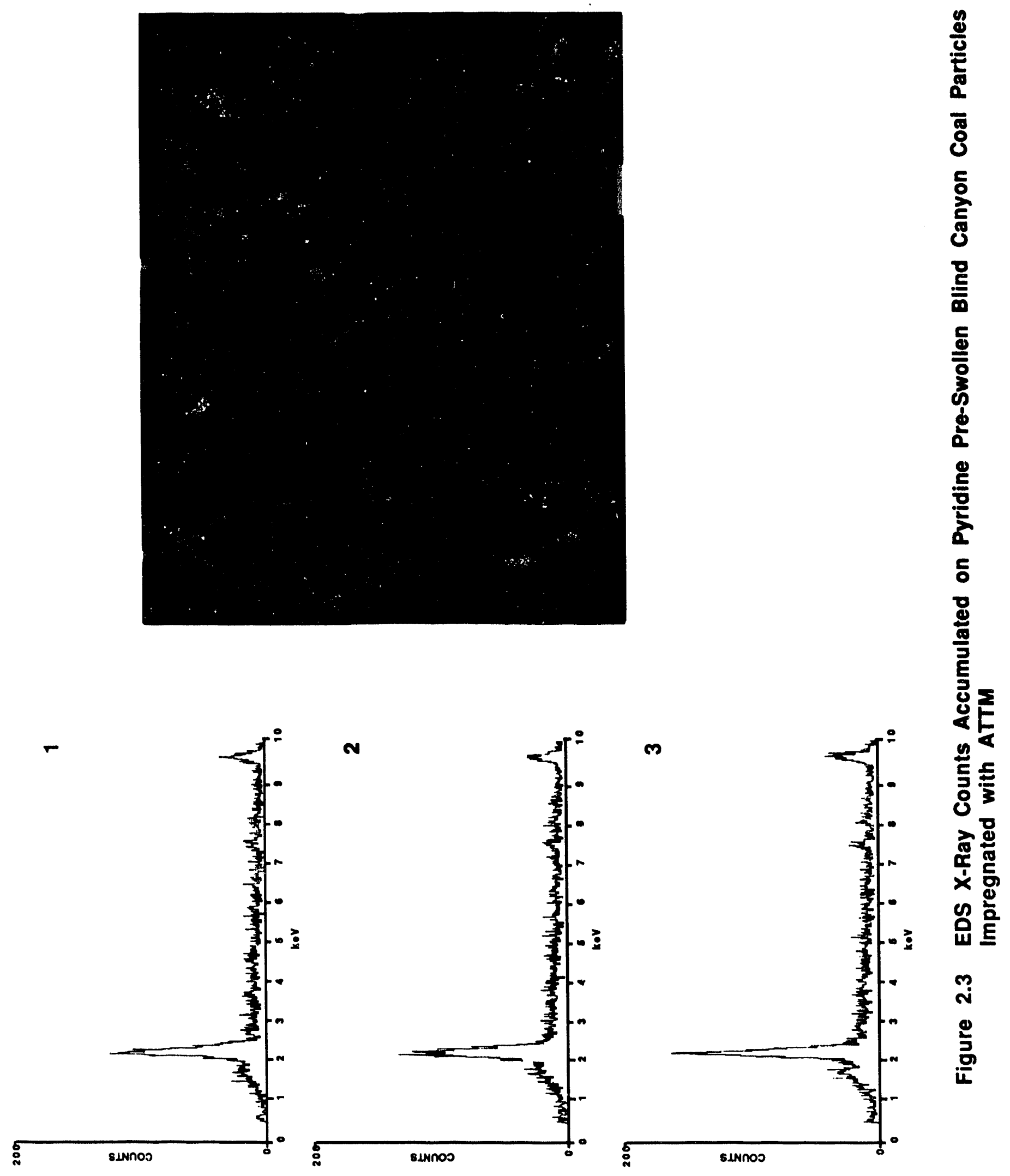


with ATTM. However, location of discrete catalyst particles associated with the coal surface was not altogether successful. As shown in Figure 2.3 for the coal preswollen in pyridine, energy spectra appear to be very uniform from site to site, with a relatively low gold peak and a large low energy peak. From this evaluation we were uncertain whether the low energy peak was being influenced by $S$ or Mo or by both $S$ and Mo. Most of the coal particles in the pyridine swollen Blind Canyon sample gave this same uniform spectra. On the other hand, spectra collected for the Blind Canyon samples swollen with methanol and THF were not so uniform. In fact, there was some difficulty in locating low energy $X$-rays from these samples, which suggests that catalyst dispersion may be heterogeneous. Clearly, a more quantitative characterization of these samples was needed and this was the reason for the electron microprobe analysis.

It has been reported (2), that in the presence of ATTM that there was little improvement in total conversion of the Blind Canyon samples under pretreatment conditions when any of these solvents (pyridine, methanol or THF) were used. However, there was a marked change in the product slate with THF and pyridine which showed relatively higher oiltgas yields. One reason for improved product yield for the THF-treated Blind Canyon sample is illustrated in Figure 2.4. The SEM micrograph shows the surface of several coal particles coated with hemispherical bodies. These bodies were easily destroyed by a focused electron beam and are carbon-rich. We concluded that this material was part of the THF-soluble fraction that was extracted from the coal during swelling and that was subsequently 


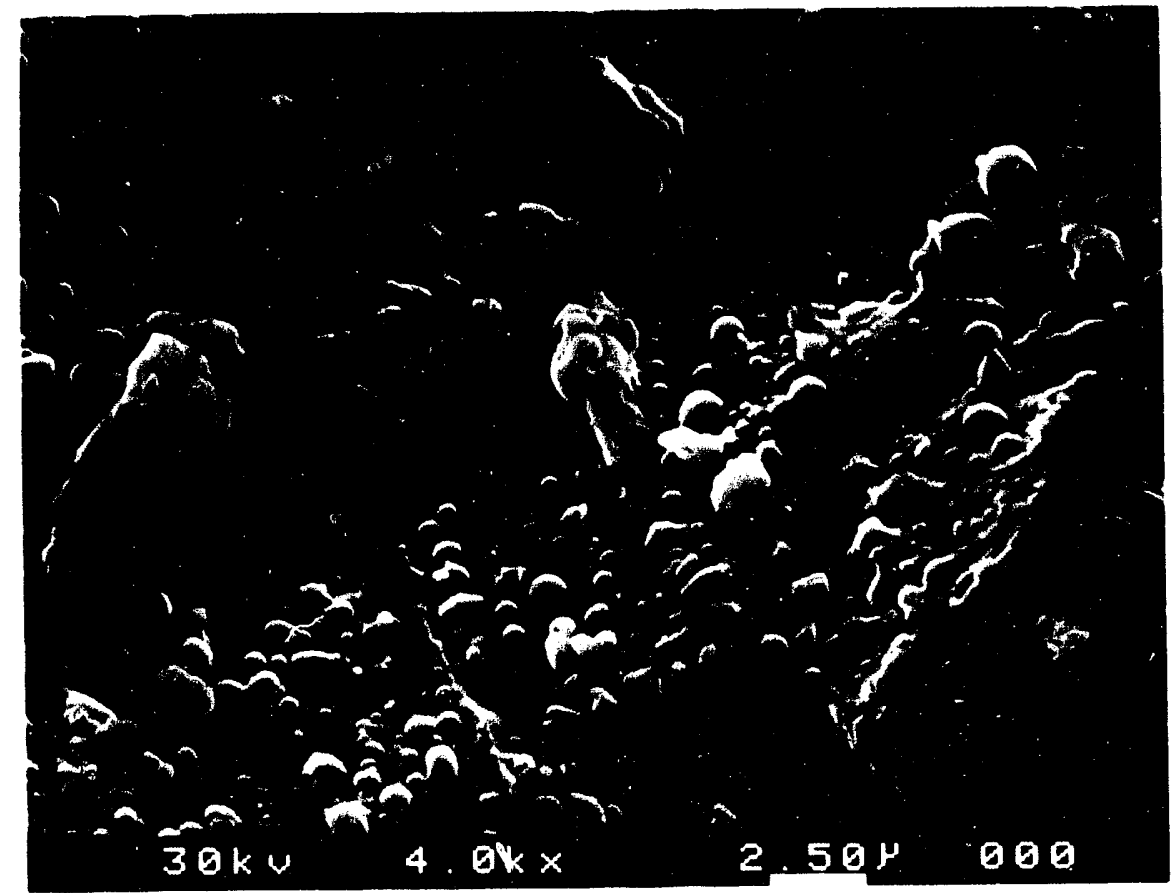

Figure 2.4 Hemispherical THF-Soluble Deposits on Coal Surface Following Coal (DECS-6) Swelling in THF with Subsequent Impregnation with ATTM 
redeposited on the coal surface when the THF was evaporated before catalyst impregnation.

The THF-soluble material has been separated from the coal during swelling, and in so doing has created more surface area for catalyst deposition. The significant increase in oiltgas yield (2) suggests that improving access of the THF-soluble fraction to the hydrogenation environment may be beneficial. An improved oiltgas yield and reduced preasphaltene and asphaltene yields implies that the increased surface area for catalyst/coal contact resulting from swelling and extraction in THF has little influence on conversion of the THF-insoluble fraction of this coal under pretreatment condition. Improved access of catalyst to the THFsoluble fraction does not significantly increase yield relative to the noncatalytic reaction, but may improve the overall product quality.

In addition to the Blind Canyon samples two Texas lignite particulate samples preswollen in methanol and pyridine and that were impregnated with ATTM were evaluated using the SEM technique. Unfortunately, there was significant interference from the presence of other elements $(\mathrm{Ca}, \mathrm{Al}, \mathrm{Si}$, $\mathrm{Ti}$, etc.) that Mo and $\mathrm{S}$ peaks were difficult to locate or interpret. In the case of the pyridine-swollen sample, not a single particle gave a Mo or $S$ peak. Consequently, all ATTM impregnated samples were prepared for electron microprobe analysis.

Microprobe measurements were made by identifying an individual coal particle using the probe white-light optics, then impinging the electron beam on the center of the particle and collecting X-ray counts for $20 \mathrm{sec}$ 
fur each element ( $S$ and Mo). Between 5 and 8 particles were analyzed in this manner for each sample. This analytical procedure will not provide an indication of catalyst impregnation vs. dispersion, but it will aid in our determination of whether the catalyst is or is not associated with individual coal particles.

Table 2.1 lists the results from these analyses and tends to confirm the qualitative evaluation performed using the SEM. For the ATTM impregnated Blind Canyon samples, molybdenum and sulfur peaks were measured for all particles tested $(100 \%)$ when the coal was not first subjected to swelling solvents. About $80 \%$ of the pyridine particles had a low level of molybdenum associated with them, whereas most $(75 \%)$ of the particles tested in the methanol swollen coal showed no molybdenum peaks. In comparison, particle mounts of the Texas lignite sample preswollen in methanol and pyridine showed that about $80 \%$ of the methanol sample had associated molybdenum and sulfur, whereas none was detected on the pyridine swollen coal. The relative intensity of the molybdenum peak presented in Table 2.1 suggested that in most cases Mo was in fairly low concentration with respect to the mass tested. This could reflect a submicron dispersion of the catalyst in and about the coal particle surface layers. The relative intensity of sulfur was found to be much more variable which probably reflects the distribution of organically bound sulfur as well as, perhaps sulfur dissociated from the ATTM catalyst following impregnation. 
Table 2.1. Electron Probe Results from ATTM Impregnated Blind Canyon and Texas Lignite Coals

\begin{tabular}{|c|c|c|c|c|c|}
\hline \multirow[b]{2}{*}{$\begin{array}{l}\text { Particle } \\
\text { No. }\end{array}$} & \multicolumn{3}{|c|}{ Elements Detected } & \multirow[b]{2}{*}{$\begin{array}{c}\text { Relative Strength } \\
\text { of Mo Peak }\end{array}$} & \multirow[b]{2}{*}{$\begin{array}{c}\text { Relative Strength } \\
\text { of S Peak }\end{array}$} \\
\hline & Mo & $S$ & Other (EDS) & & \\
\hline \multicolumn{6}{|c|}{ DECS-6 -- Not Swollen } \\
\hline 1 & * & * & -- & 4.8 & 53.6 \\
\hline 2 & $\star$ & * & $\mathrm{Al}, \mathrm{Si}$ & 6.1 & 51.6 \\
\hline 3 & * & * & -- & 9.1 & 63.3 \\
\hline 4 & * & * & -- & 38.0 & 170.8 \\
\hline 5 & * & * & -- & 7.0 & 70.0 \\
\hline 6 & * & * & -- & 7.7 & 51.2 \\
\hline \multicolumn{6}{|c|}{ DECS-6 -- Pyridine } \\
\hline 1 & * & * & -- & 7.3 & 39.8 \\
\hline 2 & $\star$ & * & $\mathrm{Al}, \mathrm{Si}, \mathrm{Cl}$ & 2.5 & 20.6 \\
\hline 3 & None & None & - & -- & -- \\
\hline 4 & * & * & -- & 3.9 & 24.7 \\
\hline 5 & $\star$ & $\star$ & -- & 4.3 & 39.2 \\
\hline \multicolumn{6}{|c|}{ DECS-6 -- Methanol } \\
\hline 1 & * & * & $\mathrm{Al}, \mathrm{Si}, \mathrm{Ca}$ & 11.2 & 67.7 \\
\hline 2 & None & None & $\mathrm{Al}, \mathrm{Si}$ & -- & -- \\
\hline 3 & * & * & $\mathrm{Al}, \mathrm{Si}, \mathrm{Ca}$ & 1.1 & 14.8 \\
\hline 4 & None & None & -- & - & - \\
\hline 5 & None & None & -- & -- & -- \\
\hline 6 & None & $\star$ & $\mathrm{Al}, \mathrm{Si}, \mathrm{S}, \mathrm{Ca}$ & -- & 5.1 \\
\hline 7 & None & None & $\mathrm{Al}, \mathrm{Si}, \mathrm{Ti}, \mathrm{Ca}$ & -- & -- \\
\hline 8 & None & None & -- & -- & - \\
\hline \multicolumn{6}{|c|}{ DECS-1 -- Methanol } \\
\hline 1 & $\star$ & $\star$ & $\mathrm{Al}, \mathrm{Si}, \mathrm{Ca}$ & 6.1 & 34.6 \\
\hline 2 & None & * & $\mathrm{Al}, \mathrm{Si}$ & -- & 4.2 \\
\hline 3 & $\star$ & * & $\mathrm{Al}, \mathrm{Si}, \mathrm{Ca}$ & 5.8 & 77.4 \\
\hline 4 & * & * & $\mathrm{Al}, \mathrm{Si}, \mathrm{Ca}$ & 6.8 & 70.2 \\
\hline 5 & * & * & $\mathrm{Al}, \mathrm{Si}, \mathrm{Ti}$ & 5.0 & 18.6 \\
\hline 6 & $\star$ & * & $\mathrm{Ca}$ & 4.7 & 57.6 \\
\hline \multicolumn{6}{|c|}{ DECS-1 - Pyridine } \\
\hline 1 & None & * & -- & -- & 4.1 \\
\hline 2 & None & * & -- & -- & 20.4 \\
\hline 3 & None & $\star$ & -- & -- & 2.6 \\
\hline 4 & Nione & $\dot{\star}$ & -- & - & $2 . \overline{8}$ \\
\hline 5 & None & $\star$ & -- & -- & 2.8 \\
\hline
\end{tabular}




\subsection{Conclusions}

Both qualitative SEM and quantitative electron microprobe analyses were performed on Blind Canyon and Texas lignite samples that were first swollen in various solvents and then impregnated with ATTM. Our results show that water- and pyridine-swollen coals may provide a better dispersion of ATTM catalyst on a submicron level on the Blind Canyon coal than when swollen in methanol. When no swelling reagent was used, the catalyst was found as discrete particles on the coals surface, but fairly uniformly distributed. ATTM was dispersed more evenly on the water and methanol preswollen Texas lignite then when pyridine was used.

References

1. Davis, A. Schobert, H.H., Mitchell, G.D. and Artok, L., (1990). Catalyst Dispersion and Activity Under Conditions of TemperatureStaged Liquefaction, DOE Technical Progress Report for the Period July to September, 1990, No. DOE-PC-89877-4.

2. Davis, A. Schobert, H.H., Mitchell, G.D. and Artok, L., (1991). Catalyst Dispersion and Activity Under Conditions of TemperatureStaged Liquefaction, DOE Technical Progress Report for the Period October to December, 1990, No. DOE-PC-89877-5. 


\section{EVALUATION OF MATERIALS FROM OTHER DOE PROGRAMS}

\subsection{Introduction}

Three reactor-solid deposit samples were received from the Wilsonville Pilot Plant on 1-28-91 for optical and mineralogical characterization. These samples were removed from the plant following the conclusion of run 260 (operating period $7 / 17-11 / 13 / 90$ ) which was operated in the catalytic/thermal mode with a feed of Black Thunder mine (Wyodak Anderson seams) subbituminous coal, at a feed rate of $350 \mathrm{MF} 1 \mathrm{~b} / \mathrm{h}$, and using a disposable iron oxide catalyst $\left(\mathrm{Fe}_{2} \mathrm{O}_{3}\right)$ added at $2 \mathrm{wt} \% \mathrm{MF}$ coal with a sulfiding agent (di-tertiary-nonly-polysulfide, $\mathrm{C}_{9} \mathrm{H}_{19} \mathrm{~S}_{x} \mathrm{C}_{9} \mathrm{H}_{19}$ ) in conjunction with the first stage catalyst (Shell $324,1 / 16^{\prime \prime}$ ).

One of the stated objectives of this run was to reduce and/or eliminate the type of reactor deposits that caused operating problem during the Wilsonville run 258 (1). In that run (2), the system was shut down and the first stage reactor section and interstage separator had to be thoroughly cleaned. Reactor-solid materials provided to Penn State from run 258 revealed that mesophase-derived semicoke was largely responsible for the deposit formed from the Black Thunder coal (2). Thus, run 260 was operated in a catalytic/thermal mode with lower first-stage and higher second-stage temperatures in an attempt to prevent retrogressive reactions and coke formation. 


\subsection{Experimental}

Two of the samples (SN16411, wall deposit and SN16403, reactor bottom solid) received from Wilsonville were saturated with a sticky black resid which had to be removed before analysis. The third sample (SN16413, suction cup line) was a section of pipe containing a hard, dark gray deposit which could be cut away with a knife. The two reactor deposit samples were placed in $150 \mathrm{ml}$ of THF for $15 \mathrm{~h}$, filtered and washed with THF and methanol and dried in a vacuum oven at room temperature for $8 \mathrm{~h}$. All solids were then split into subsamples for the determination of percentage ash content, X-ray diffraction and for optical microscopy.

\subsection{Results and Discussion}

Figure 3.1 shows the location of each deposit sample within the Wilsonville thermal reactor (R1235), and Table 3.1 lists the analytical results. Wilsonville reported (1) that the first-stage catalytic reactor and the downstream line leading to the thermal reactor (R1235) were clean and free of deposits, suggesting that the operating scheme for run 260 caused the deposit problem to be shifted downstream. During inspection of the thermal reactor, considerable deposits were found on both the inside ( $1 / 4 "$ thick) and outside ( $3 / 4^{\prime \prime}$ thick) of the ebullating pump suction tube (Figure 3.1) as well as about 132 lbs of material in the bottom of the reactor.

Data in Table 3.1 shows that the reactor bottoms sample (SN16403) has a much lower amount of insoluble organic matter (IOM) than the wall deposit 


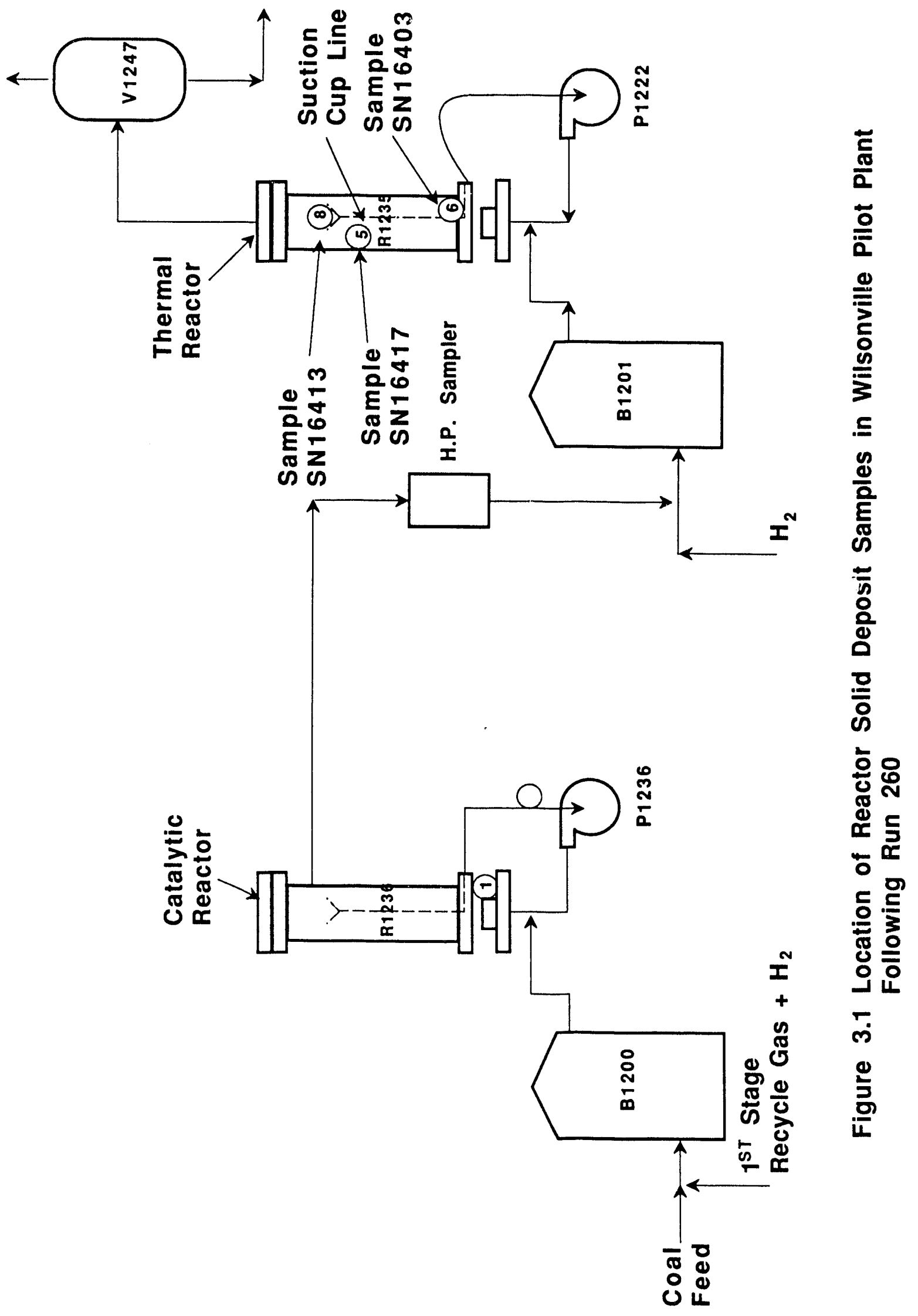




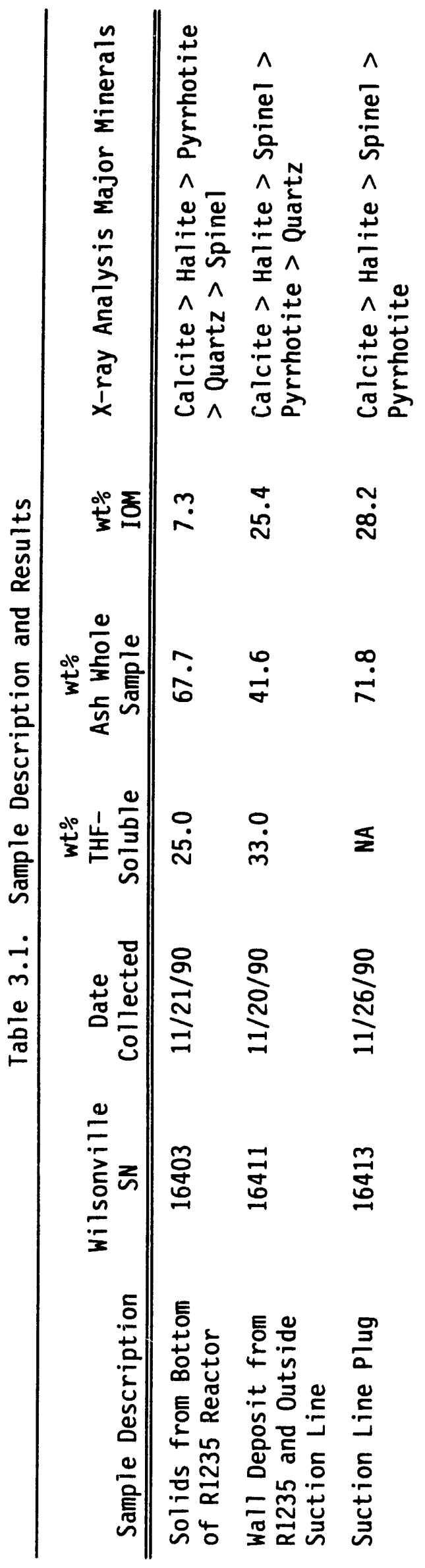


(SN16411) and suction line plug (SN16413) materials, otherwise the high ash content and sample mineralogy were found to be similar. Minerals detected by X-ray diffraction for each sample, which are listed in order of their relative concentrations based on peak intensities, were very similar. Calcite $\left(\mathrm{CaCO}_{3}\right)$, halite $(\mathrm{NaCl})$ and pyrrhotite $\left(\mathrm{Fe}_{1-\mathrm{x}} \mathrm{S}\right)$ were the predominate mineral phases found along with spinel $\left(\mathrm{MgAl}_{2} \mathrm{O}_{4}\right)$ and quartz $\left(\mathrm{SiO}_{2}\right)$. Spinel and quartz are coal-derived minerals, whereas the calcite, pyrrhotite (iron oxide catalyst) and perhaps halite are process-derived. The major surprise in this evaluation was to find halite in relatively high concentrations in these solids. Halite was also found in the Black Thunder reactor solids from run 258 even though chlorine levels for the coal were reported to be less than $0.01 \%(2)$. Again, there can be no plausible explanation for the presence of $\mathrm{NaCl}$ other than contamination with the mineral before processing or from the use of a chlorinated chemical during some phase of operations (e.g., cleaning the reactor or lines with $\mathrm{HCl}$ ).

Optical microscopy of the deposit samples showed that the reactor bottoms sample was mainly composed of calcium carbonate spheres, pyrrhotite aggregates with carbonate rims and coal-derived minerals cemented together with a thin layer of process-derived mesophase. As an example, Figure $3.2 \mathrm{a}$ shows a layer of anisotropic mesophase carbon coating the surface of process-derived vitroplast (isotropic). However, as suggested by the relatively low IOM (Table 3.1) of this sample, the accretion of calcium carbonate appeared to be the main cause of the deposit; deposition of mesophase may be only secondary. 

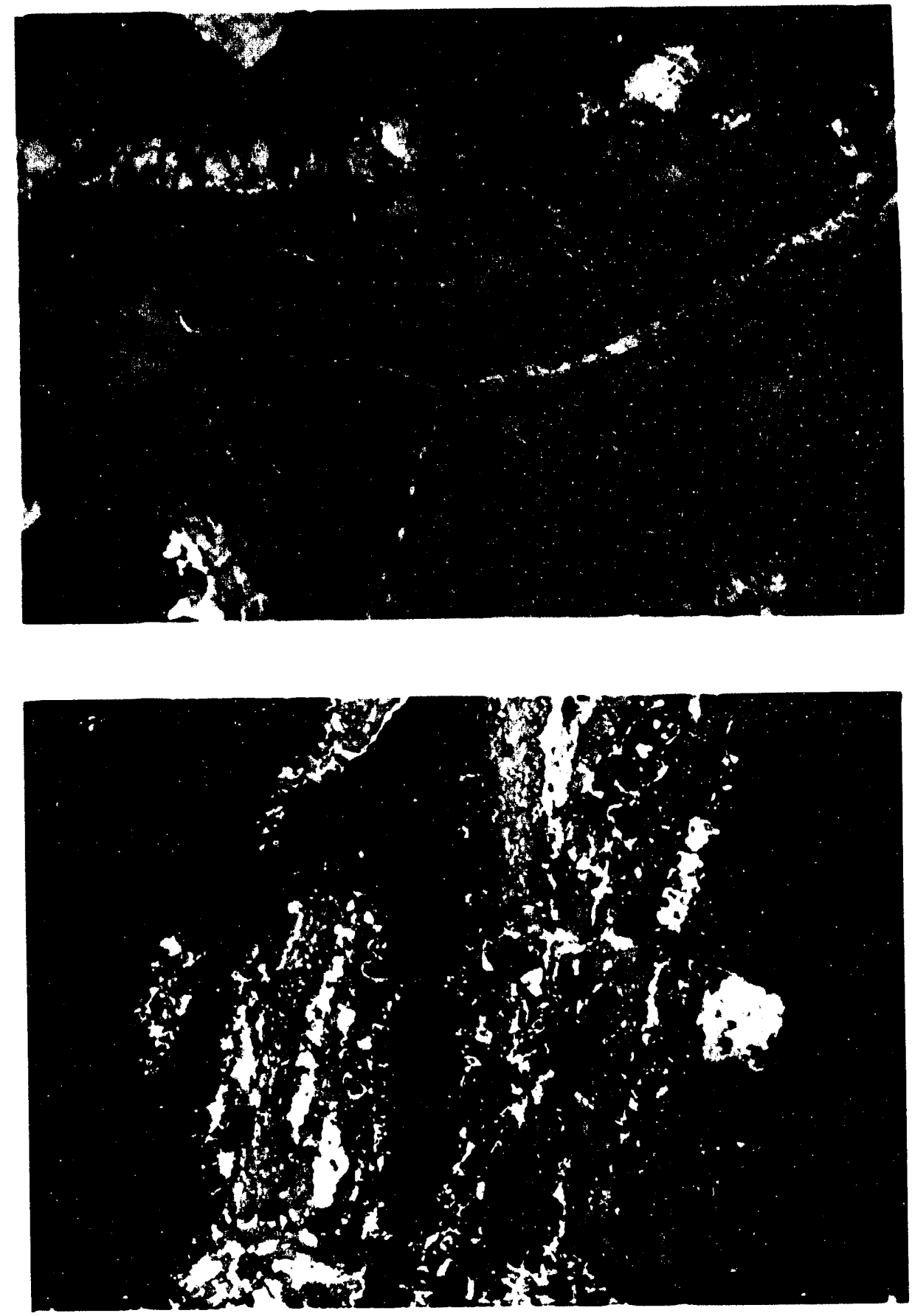

\section{$40 \mu \mathrm{m}$}

Figure 3.2 Wilsonville Reactor Solids Material from Run 260 with Black Thunder Coal,

a.) Particle of Secondary Vitroplast Coated with Mesophase Carbon (SN16403)

b.) Intimate Association of Pyrrhotite, Vitroplast and Carbonate Cement in SN16413 
The wall deposit and suction line plug samples appeared to be very similar under the optical microscope, in that both samples were composed predominantly of a calcium carbonate cement. Figure $3.2 \mathrm{~b}$ shows the interrelationship between some of the organic material (secondary vitroplast), pyrrhotite and the carbonate cement. Most of the IOM in these two samples were found to be isotropic vitroplast and coal-derived inertinite instead of mesophase. This suggests that the process conditions selected by Wilsonville to prevent coking reaction may indeed have been effective. Production of an isotropic carbon was favored instead of an anisotropic organic insoluble material. However, the larger problem of carbonate formation may not be alleviated by altering process conditions, but only be the removal of the organically bound calcium ions prior to liquefaction.

\subsection{Conclusions}

As part of our cooperative research effort with other DOE contractors, samples of reactor deposit materials were obtained from the Wilsonville Pilot Plant. These deposits accumulated during run 260 in which the subbituminous Black Thunder mine coal was being reacted in a catalytic/thermal mode with lower first-stage and higher second-stage temperatures. Materials accumulated solely in the second-stage thermal reactor at the bottom and as deposits on the wall and the outside and inside of the ebullating suction line.

Following the characterization of three samples by $X$-ray diffraction 
and optical microscopy, we conclude that the deposits were mainly formed as a result of the formation and accretion or deposition of calcium carbonate with the other available process- and coal-derived inerts. Formation of mesophase-derived carbon was found to be minimized, but there was a proportionally greater amount of secondary vitroplast observed. This suggests that the process conditions selected by Wilsonville to eliminate retrogressive coking reactions was effective in reducing mesophase production, but did not totally alleviated the production of insoluble organic inerts. Furthermore, the larger problem of the formation of process-derived calcium carbonate has not, and may not be addressed by altering process conditions, but may require the removal of organically bound calcium ions before liquefaction.

\section{References}

1. Southern Clean Fuels, Wilsonville Advanced Coal Liquefaction $R \& D$ Facility, Handouts from Technical Meeting No. 108, January 17, 1991, pp.57.

2. Davis, A. Schobert, H.H., Mitchell, G.D. and Artok, L., (1990). Catalyst Dispersion and Activity Under Conditions of TemperatureStaged Liquefaction, DOE Technical Progress Report for the Period April to June, 1990, No. DCE-PC-89877-3. 

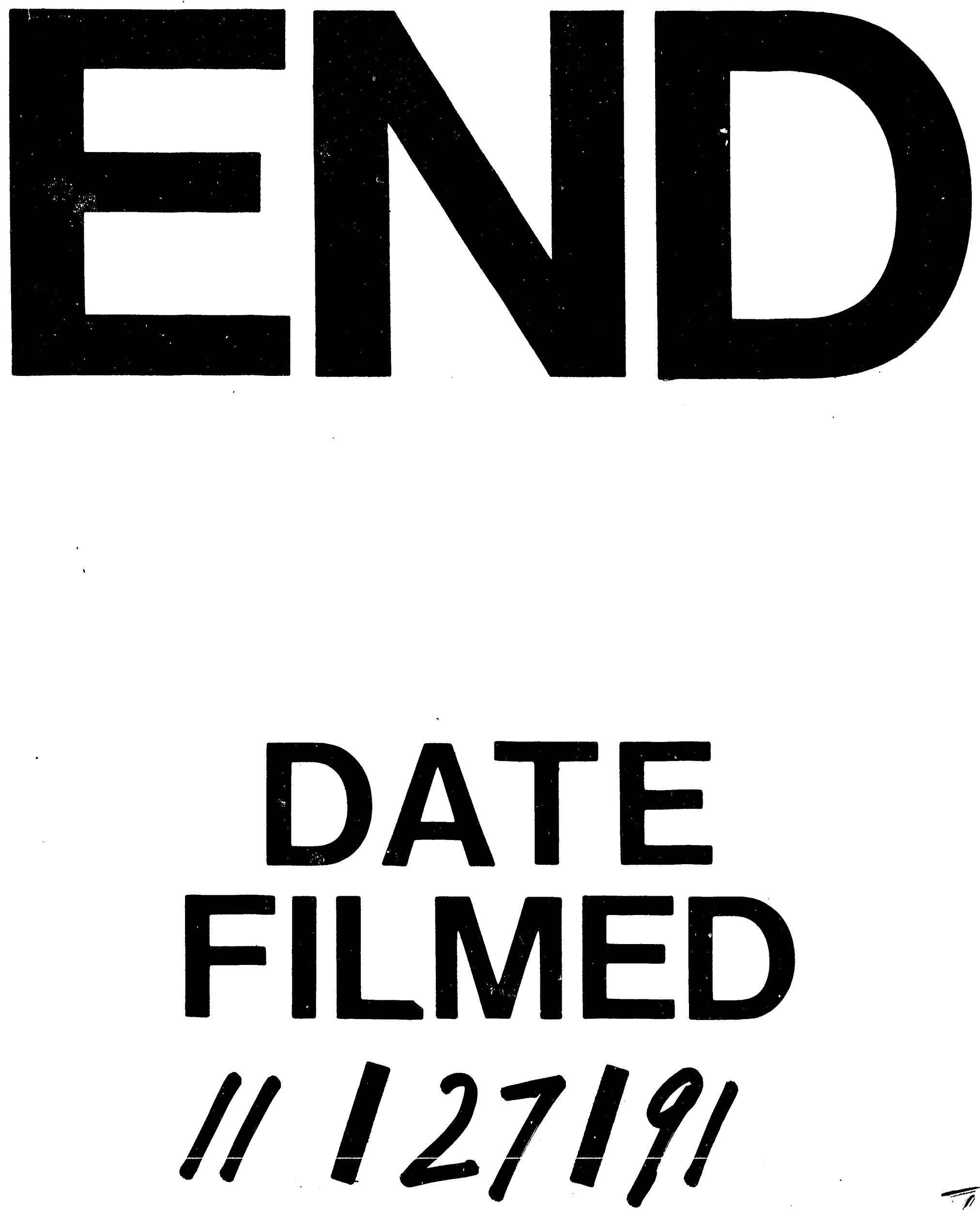

। 
